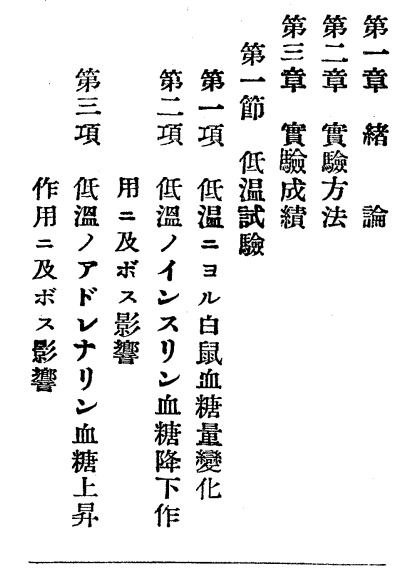

第 第

附五四 章章 第 第第
鈗結
總 項 考結總 項 項項高

献势作高用高高溫

諭ビ用溫二溫温試

考二ノ及

按及アボイ

ボドスンル

スレ影ス白

影ナ響り鼠

響りン血

血 糖

血糖降量

椟篮

次

目

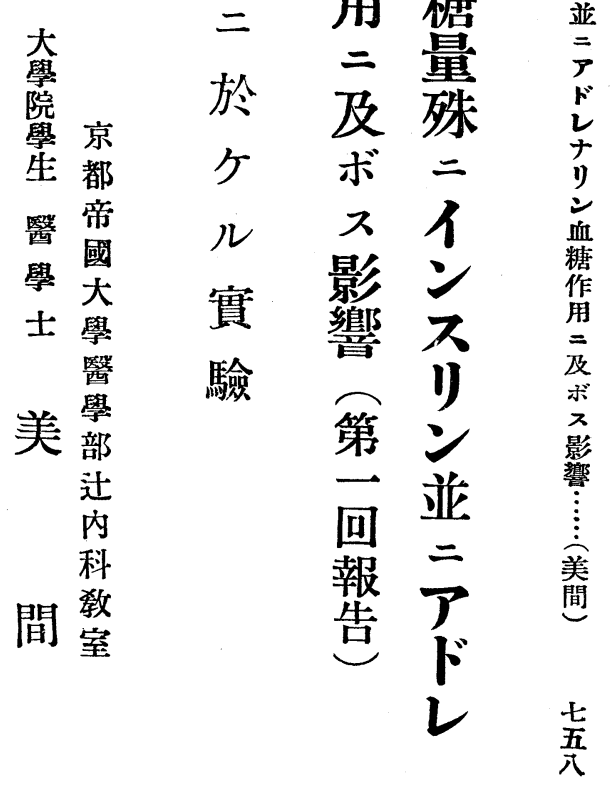

武

述 


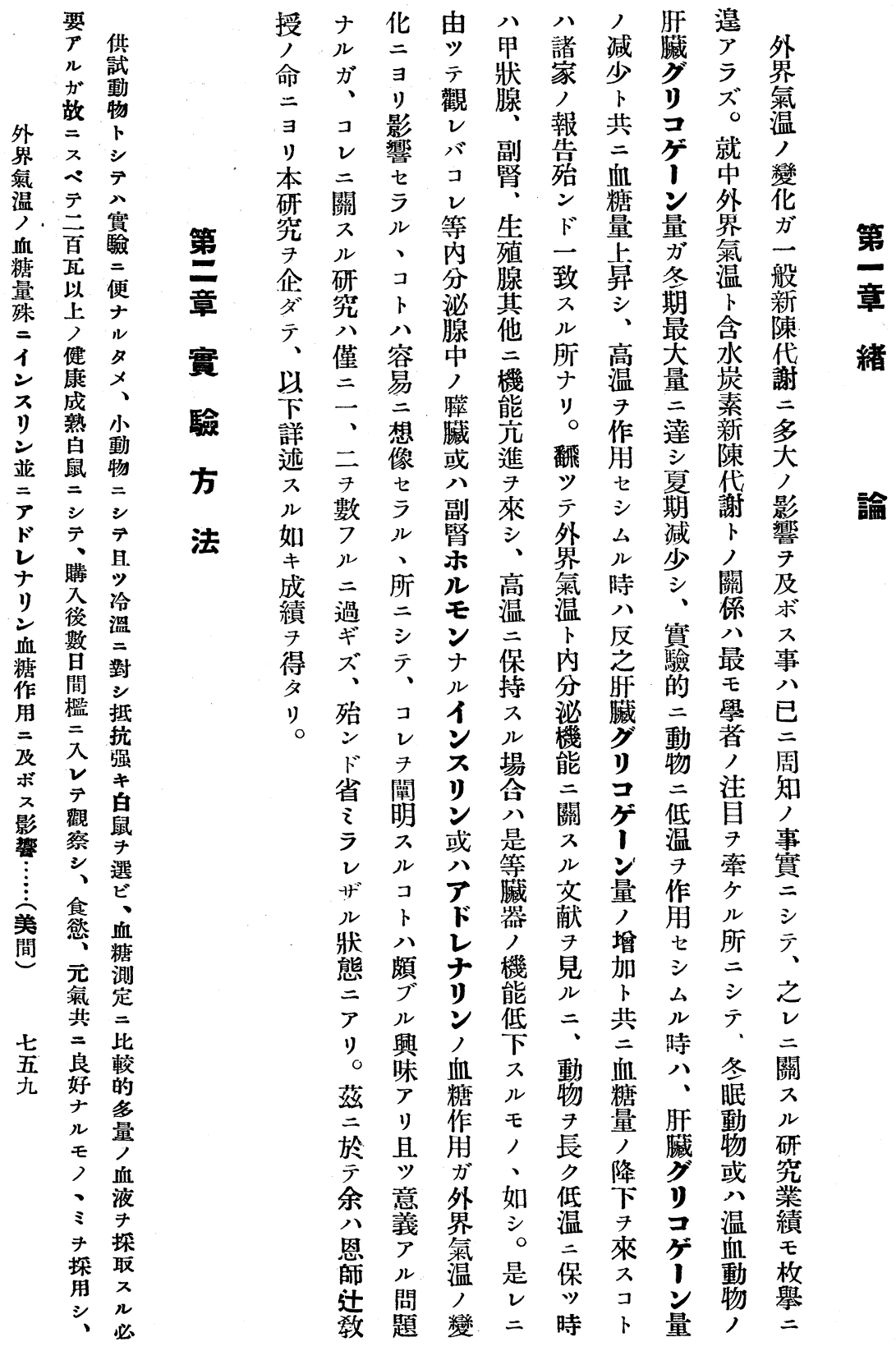




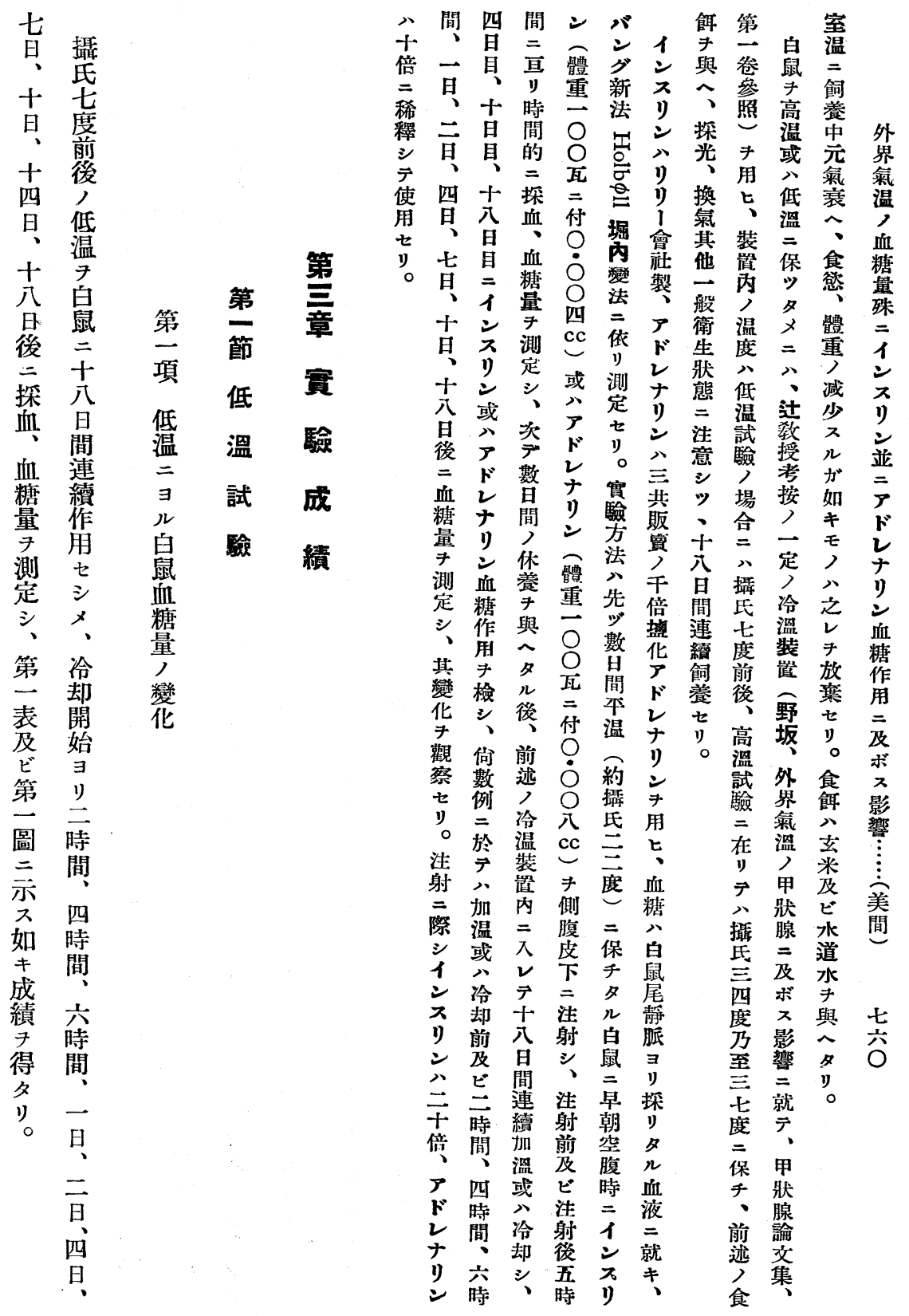




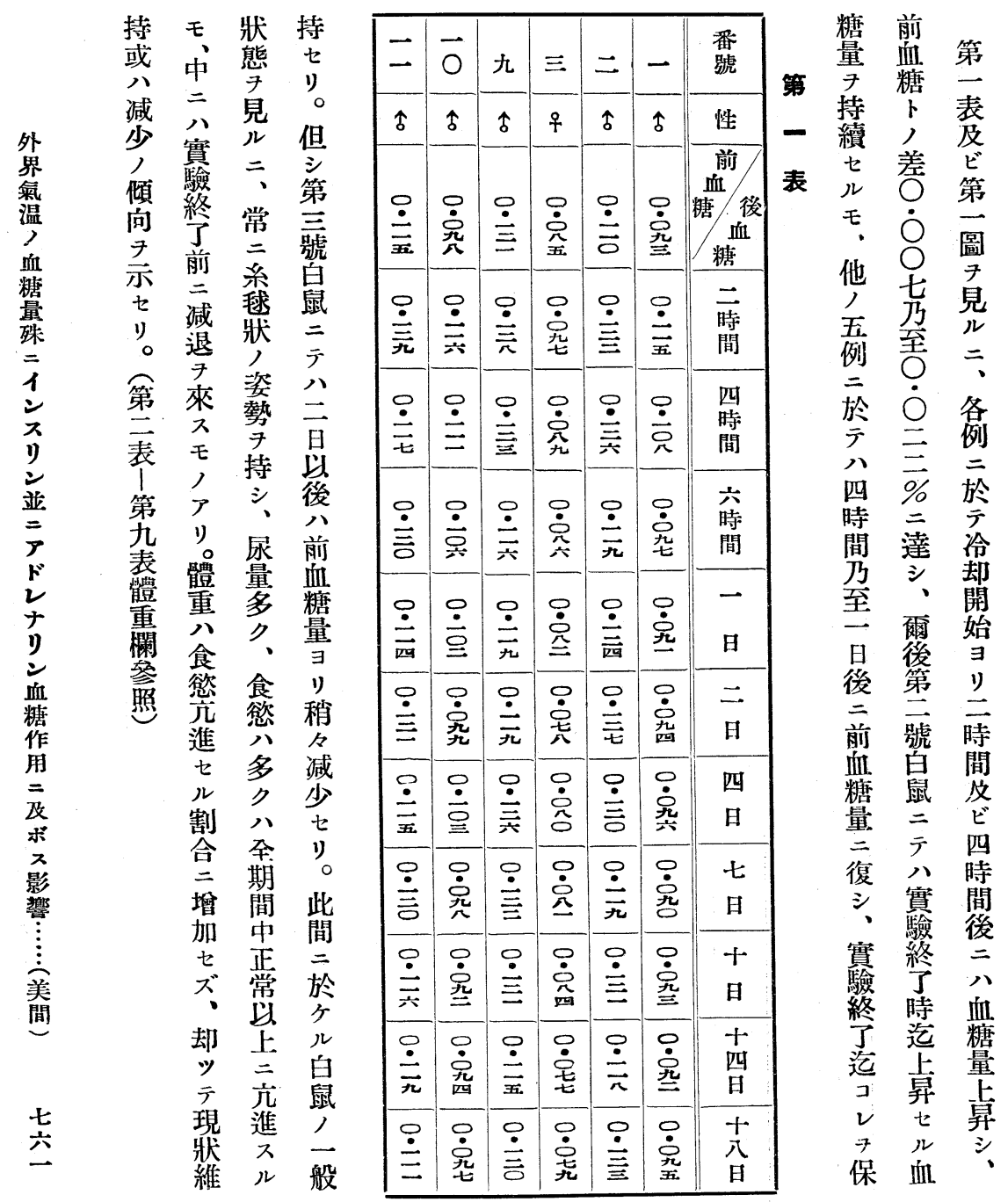

第一圖 第一表, 第一號白鼠ノ血糖曲線

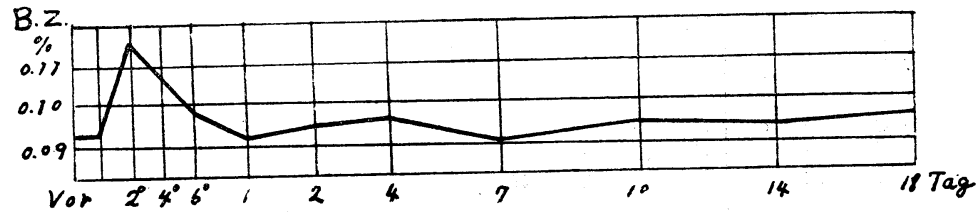




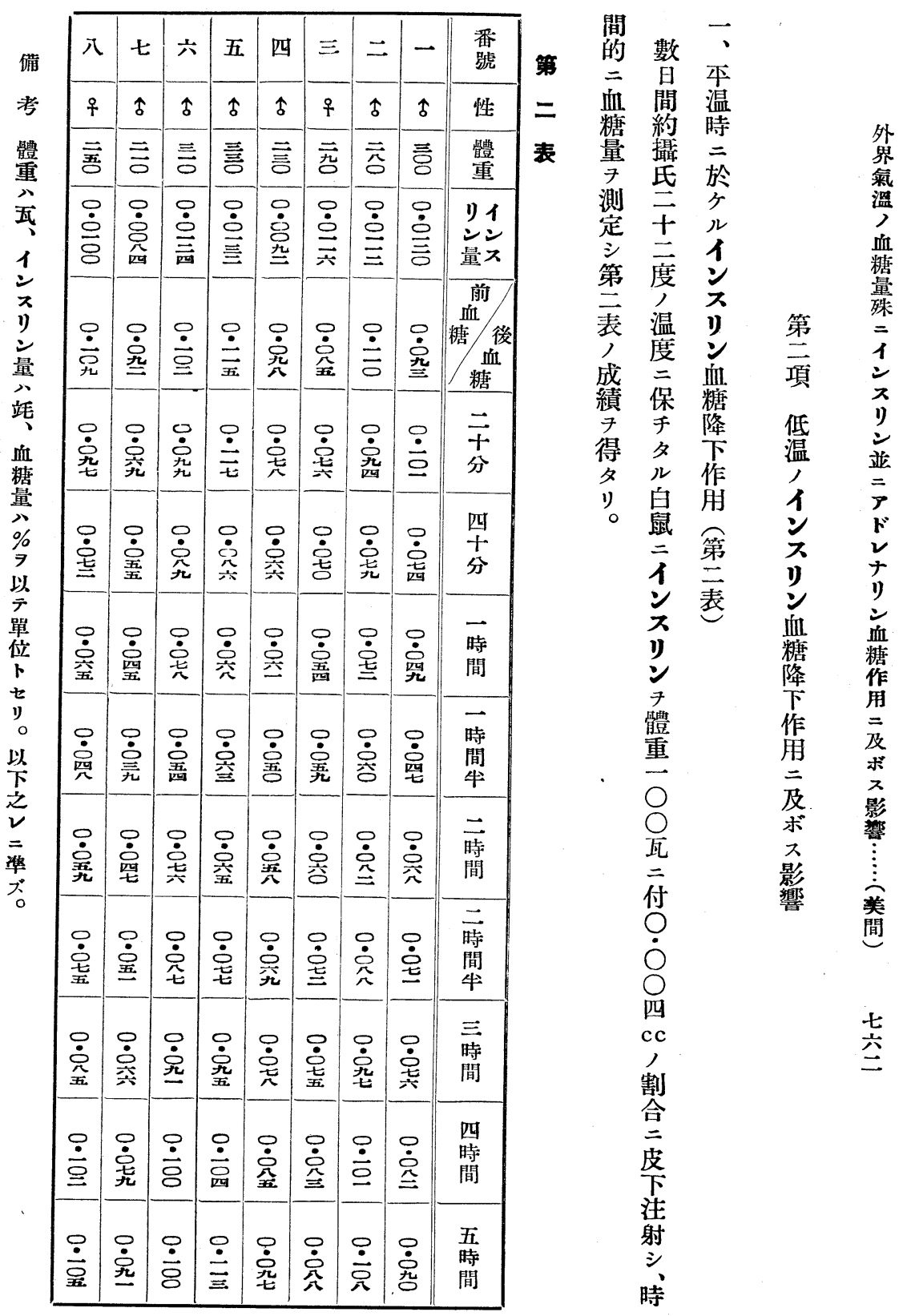




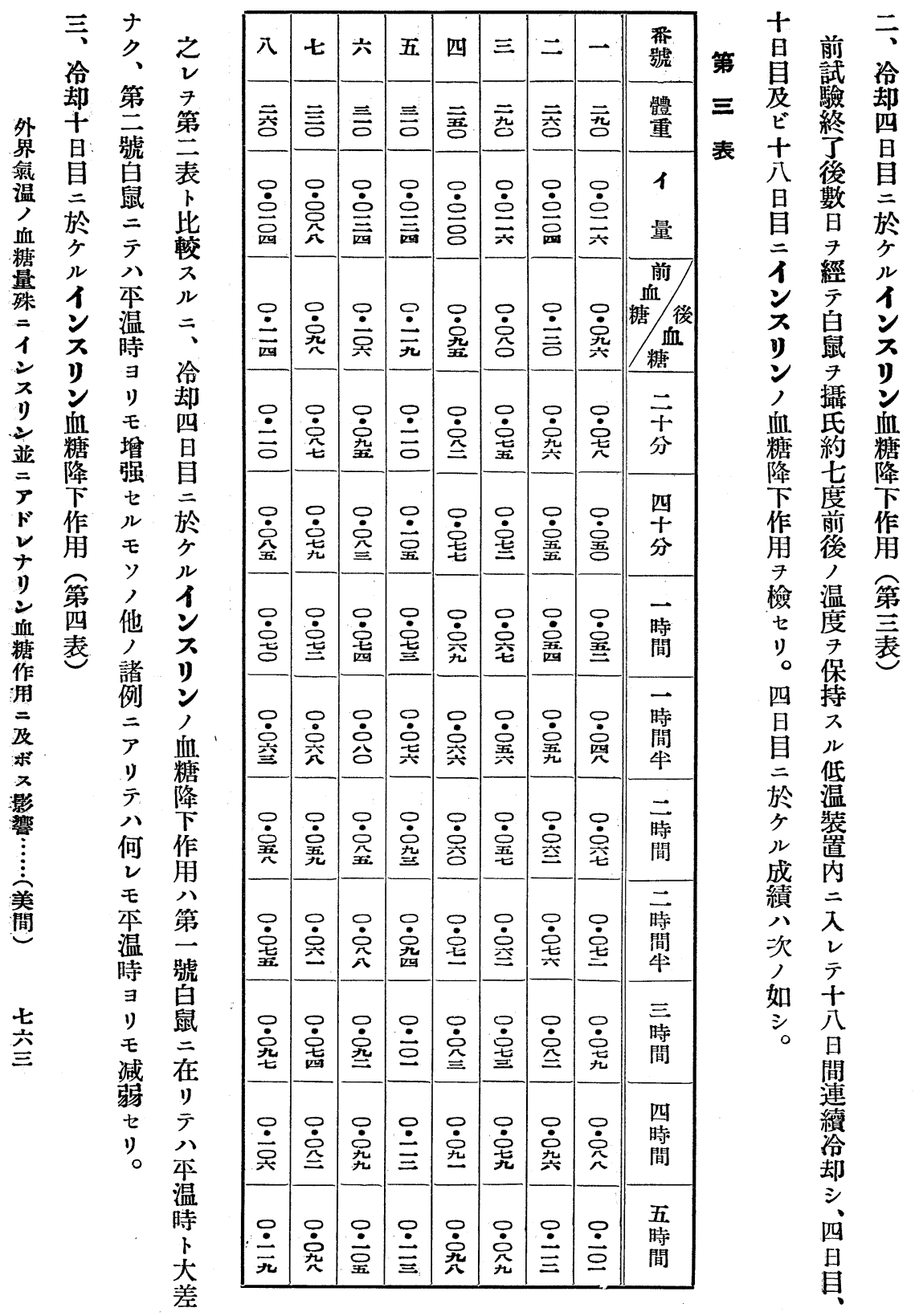




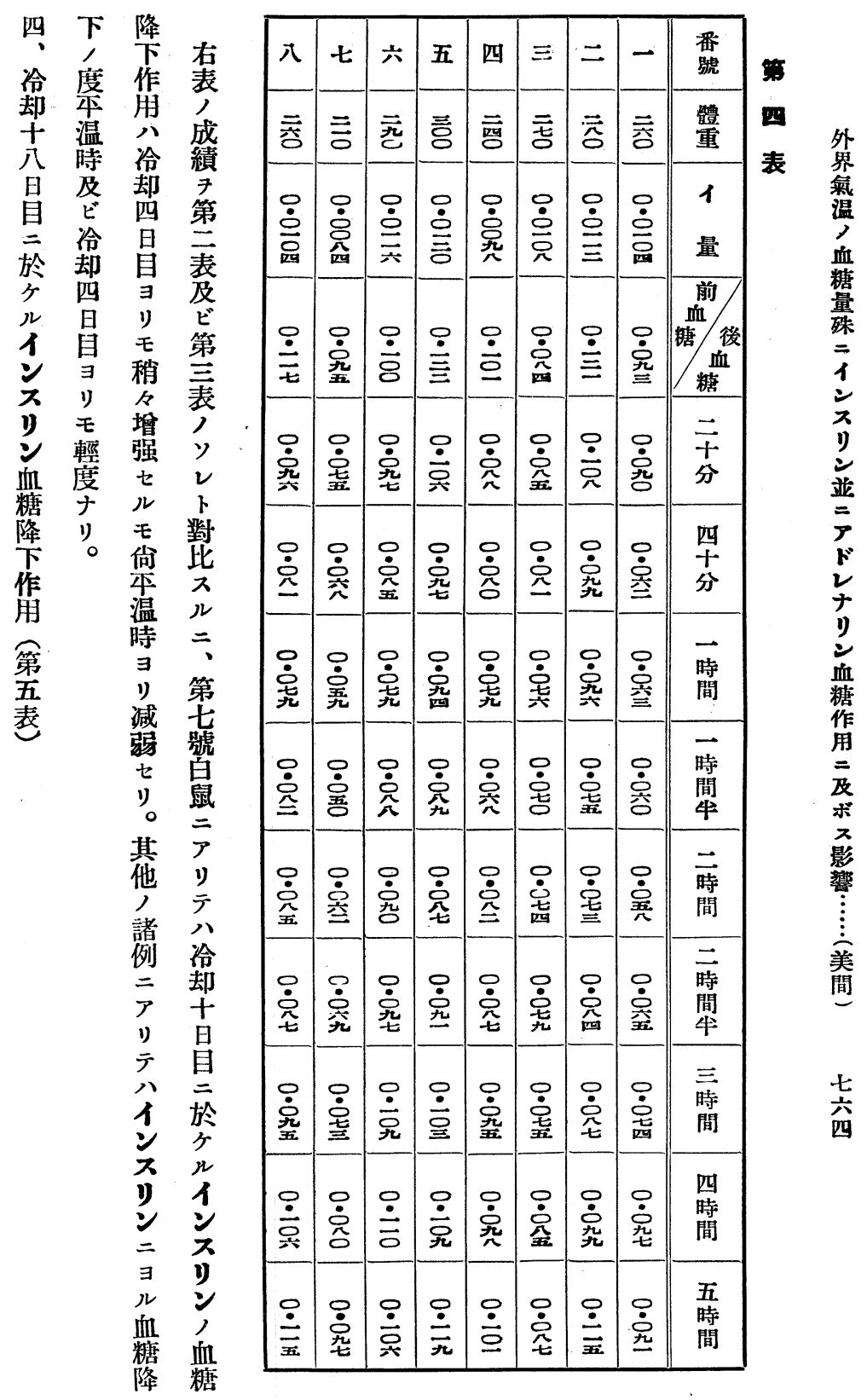




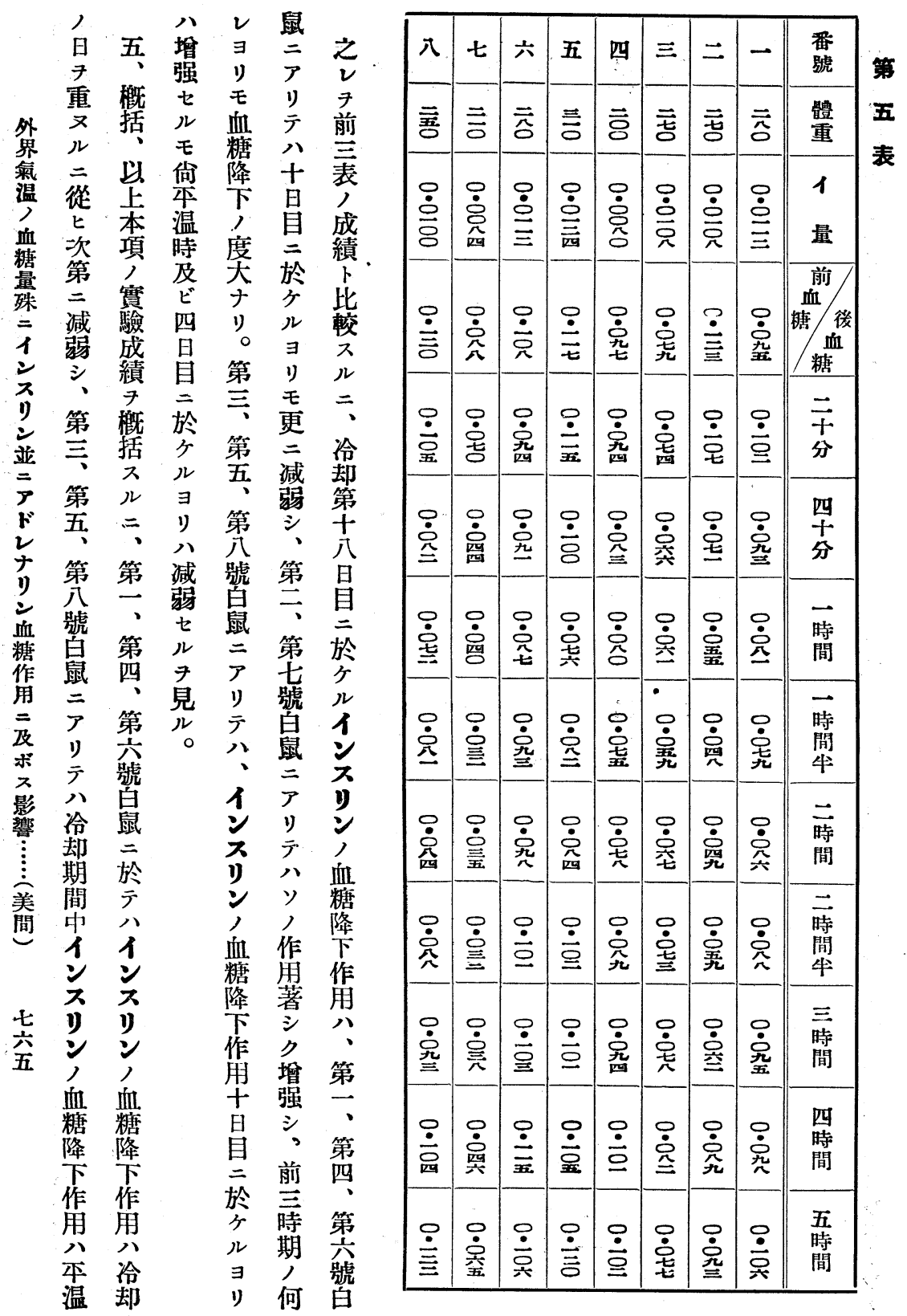


（第四號白鼠）
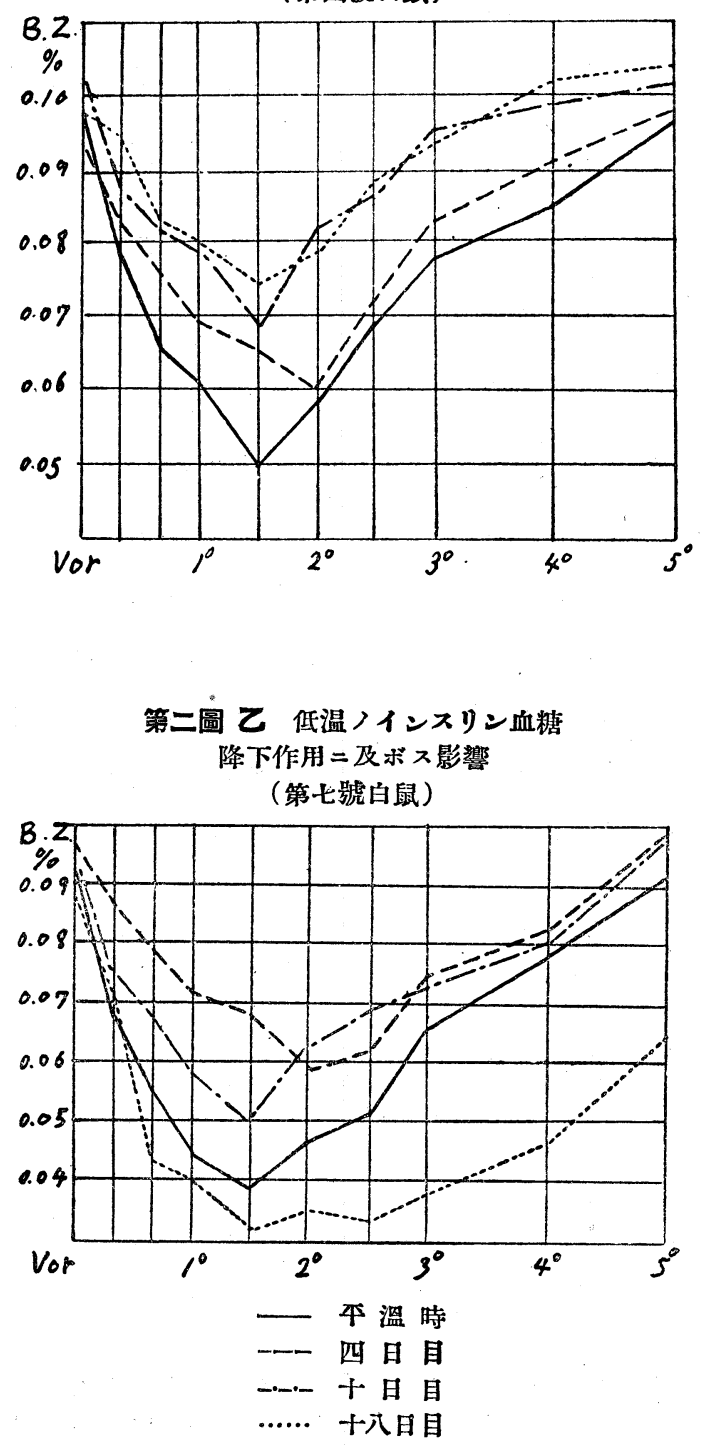

乙低温ノインスリン血糖 降下作用二及ボス影響

（第七號白鼠） 


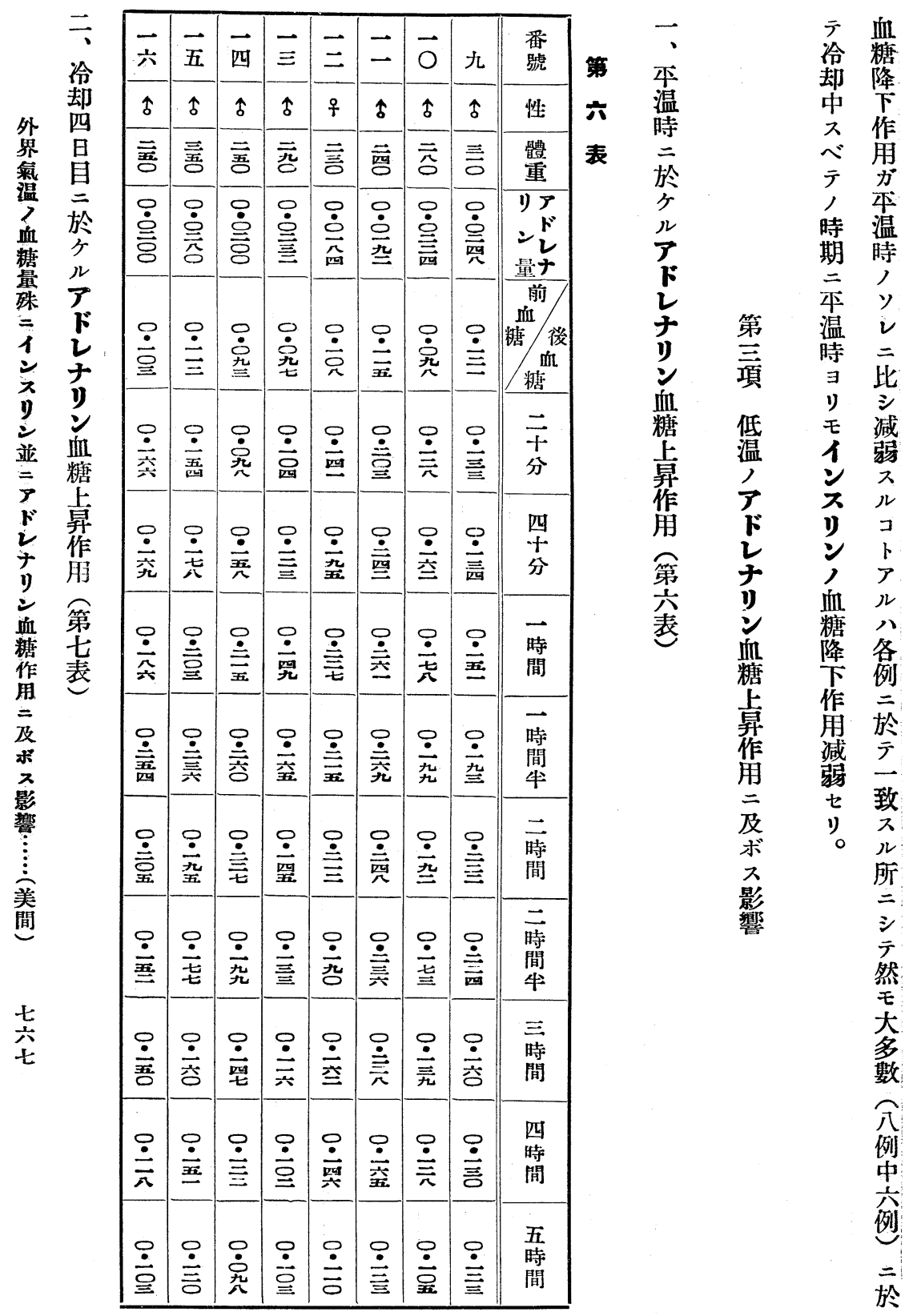




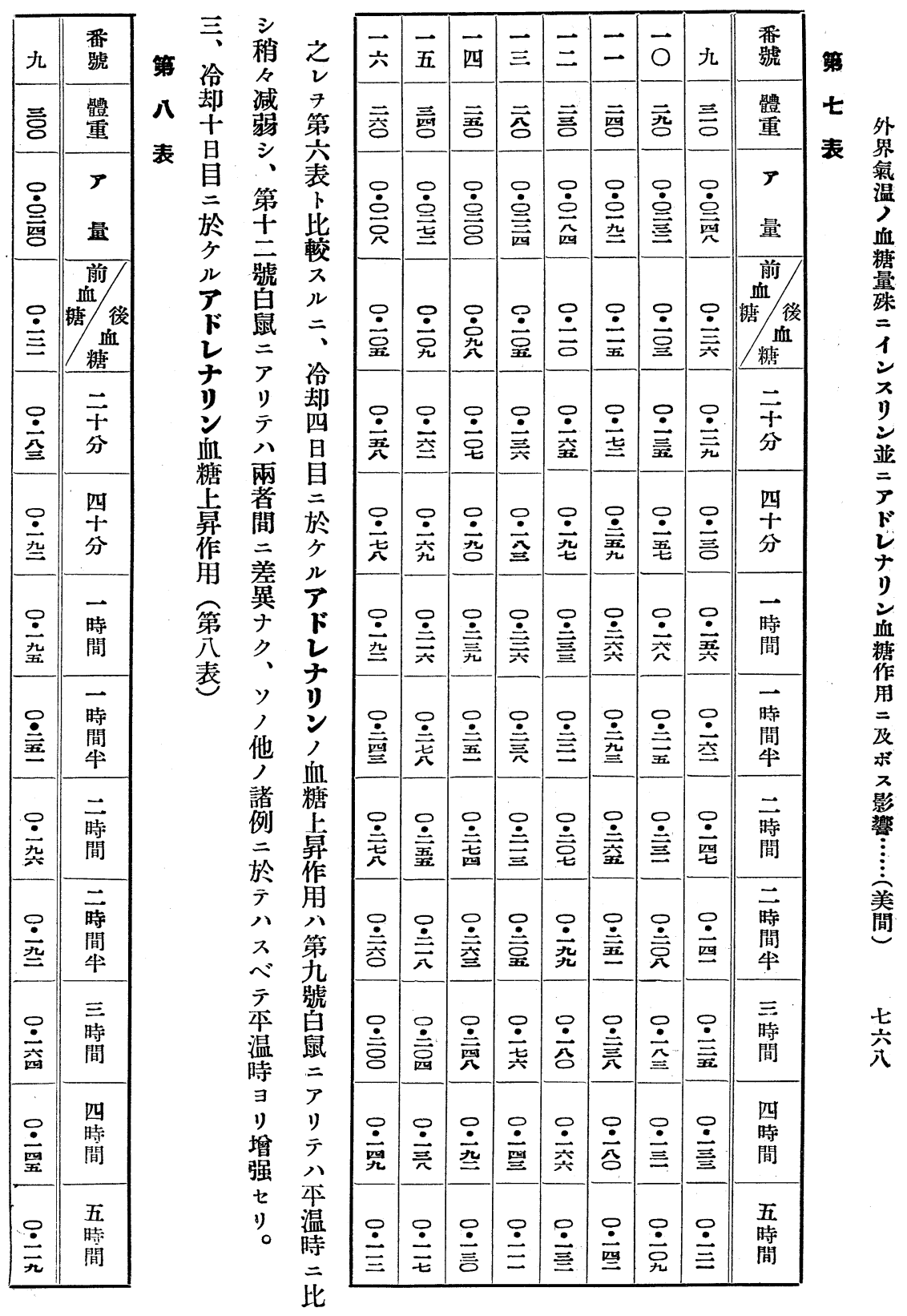




\begin{tabular}{|c|c|c|c|c|c|c|c|c|c|c|c|c|c|c|c|}
\hline$\Rightarrow$ & $\overrightarrow{0}$ & 九 & $\begin{array}{l}\text { 番 } \\
\text { 號 }\end{array}$ & 第 & 四 & 立 & & 右 & $\overrightarrow{\text { 六 }}$ & $\overrightarrow{\text { 五 }}$ & $\overrightarrow{\text { 四 }}$ & $\vec{\equiv}$ & $\equiv$ & $\vec{z}$ & $\overrightarrow{0}$ \\
\hline 亜 & $\overline{\bar{E}}$ & 完 & $\begin{array}{l}\text { 體 } \\
\text { 乯 }\end{array}$ & 九 & $\begin{array}{l}\text { 却 } \\
+\end{array}$ & 四 & 四 & 第 & 穷 & 寰 & 吾 & 完 & 言 & 言 & 齐 \\
\hline $\begin{array}{l}\dot{\circ} \\
\dot{\rho}\end{array}$ & 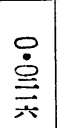 & $\begin{array}{l}\stackrel{0}{0} \\
\text { 竎 }\end{array}$ & $\begin{array}{l}\boldsymbol{\gamma} \\
\text { 量 }\end{array}$ & & $\begin{array}{l}\text { 昌 } \\
\text { 严 }\end{array}$ & $\begin{array}{c}\text { 口 } \\
\text { 於 } \\
\text { 号 } \\
u\end{array}$ & $\begin{array}{l}\text { 目 } \\
\text { 於 } \\
\text { 多 }\end{array}$ & $\begin{array}{l}\text { 教 } \\
\text { 策 } \\
\text { 第 }\end{array}$ & 导 & $\mid \begin{array}{l}0 \\
\dot{\oint} \\
\underline{\underline{E}}\end{array}$ & $\mid \begin{array}{l}0 \\
\dot{O} \\
\overline{8}\end{array}$ & 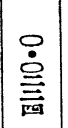 & $\begin{array}{l}\stackrel{ }{\dot{\delta}} \\
\text { 胥 }\end{array}$ & $\begin{array}{l}0 \\
\dot{0} \\
\text { 艺 }\end{array}$ & 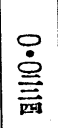 \\
\hline 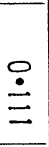 & $\begin{array}{l}0 \\
\dot{D} \\
\text { 旮 }\end{array}$ & 号 & \begin{tabular}{|c|} 
前 \\
恤 \\
盀 \\
糖 \\
\end{tabular} & & 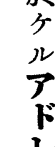 & $\begin{array}{l}\exists \\
\text { 少 } \\
\text { 更 } \\
=\end{array}$ & $\begin{array}{l}ル \\
\exists \\
\Downarrow \\
\text { N }\end{array}$ & 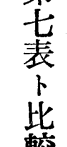 & 总 & 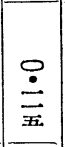 & $\begin{array}{l}0 \\
\dot{0} \\
\text { 茥 } \\
\end{array}$ & 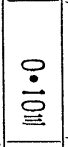 & 号 & 兰 & 号 \\
\hline 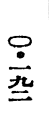 & $\begin{array}{l}\stackrel{0}{\dot{c}} \\
\text { 究 }\end{array}$ & $\stackrel{8}{\dot{\grave{c}}}$ & $\begin{array}{l}\overrightarrow{\overline{1}} \\
\text { 分 }\end{array}$ & & ) & $\begin{array}{c}\text { 强 } \\
\text { 來 }\end{array}$ & 减 & $\begin{array}{l}\lambda \\
\pi \\
=\end{array}$ & $\stackrel{8}{\stackrel{\text { 宍 }}{2}}$ & $\stackrel{\circ}{\dot{\equiv}}$ & 咅 & 兰 & 咅 & 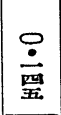 & 兰 \\
\hline$\stackrel{\circ}{\grave{\bar{O}}}$ & $\stackrel{\stackrel{ }{\dot{\lambda}}}{\stackrel{\underline{\underline{\beta}}}{2}}$ & 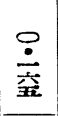 & $\begin{array}{l}\text { 四 } \\
+\frac{1}{7} \\
\text { 分 }\end{array}$ & & 梠 & y & $\begin{array}{l}\text { ル } \\
\text { モ } \\
\text { 鉴 }\end{array}$ & $\begin{array}{l}\text { 冷 } \\
\text { 却 } \\
+\end{array}$ & $\stackrel{\circ}{\stackrel{\Xi}{\equiv}}$ & 妾 & $\stackrel{\circ}{\text { 兄 }}$ & 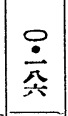 & $\stackrel{\text { 至 }}{\text { 至 }}$ & $\begin{array}{l}\text { 畜 } \\
\text { 置 }\end{array}$ & 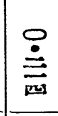 \\
\hline$\stackrel{\circ}{\stackrel{一}{\overline{0}}}$ & 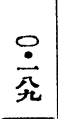 & $\stackrel{\stackrel{\rho}{\dot{t}}}{\text { 它 }}$ & $\begin{array}{l}\text { 洔 } \\
\text { 間 }\end{array}$ & & † & & $\begin{array}{c}\text { 温 } \\
\text { 時 } \\
\exists \\
\text { 》丨 }\end{array}$ & $\begin{array}{l}\text { 自 } \\
\text { 於 }\end{array}$ & 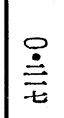 & 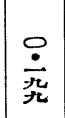 & 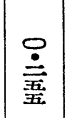 & $\stackrel{\text { 离 }}{\text { 搵 }}$ & $\begin{array}{l}\stackrel{\circ}{\dot{\jmath}} \\
\text { 范 }\end{array}$ & 号 & 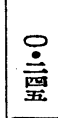 \\
\hline$\stackrel{\circ}{\text { 㺯 }}$ & 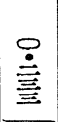 & 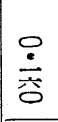 & 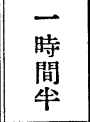 & & & & $\begin{array}{l}\text { 增 } \\
\text { 虽 }\end{array}$ & $\underset{\boldsymbol{N}}{\stackrel{R}{\boldsymbol{r}}}$ & $\begin{array}{l}\stackrel{P}{\circ} \\
\text { 产 } \\
\end{array}$ & 兰 & $\begin{array}{l}\text { 童 } \\
\text { 至 }\end{array}$ & $\begin{array}{l}0 \\
\text { 穻 } \\
\end{array}$ & $\begin{array}{l}\text { 离 } \\
\text { 曾 }\end{array}$ & 吴 & 总 \\
\hline 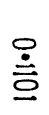 & 总 & 蒡 & $\begin{array}{l}\text { 蒔 } \\
\text { 間 }\end{array}$ & & & & $\begin{array}{l}\text { 示 } \\
\text { シ }\end{array}$ & $\begin{array}{l}\text { ナ } \\
\text { y } \\
\boldsymbol{V}\end{array}$ & 总 & 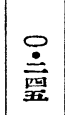 & 竞 & 竞 & 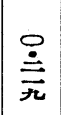 & 咅 & 昙 \\
\hline 完 & 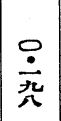 & $\stackrel{\circ}{\text { 突 }}$ & $\begin{array}{l}\text { 䙵 } \\
\text { 闍 } \\
\text { 箨 }\end{array}$ & & & & $\begin{array}{l}\text { 他 } \\
\text { 諸 }\end{array}$ & $\begin{array}{l}\text { 䘏 } \\
\text { 糖 } \\
\text { 㸴 }\end{array}$ & 訔 & $\stackrel{\circ}{\text { 言 }}$ & 章 & 竞 & $\frac{0}{a}$ & 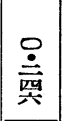 & 兰 \\
\hline$\stackrel{\stackrel{9}{\dot{x}}}{\text { 要 }}$ & 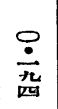 & 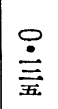 & $\begin{array}{l}\text { 夏 } \\
\text { 間 }\end{array}$ & & & & $\frac{}{\bar{\gamma}}$ & $\begin{array}{l}\text { 作 } \\
\text { 公 }\end{array}$ & 竞 & 突 & 竞 & $\mid \begin{array}{c}0 \\
\dot{\vec{z}} \\
t\end{array}$ & 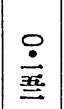 & 昙 & 竞 \\
\hline 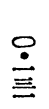 & 呈 & 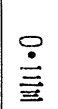 & $\begin{array}{l}\text { 四 } \\
\text { 時 } \\
\text { 間 }\end{array}$ & & & & $\begin{array}{l}\text { 永 } \\
\text { 何 }\end{array}$ & $\begin{array}{l}\text { 第 } \\
+\end{array}$ & 咅 & 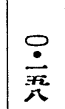 & 安 & 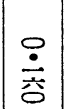 & $\mid \begin{array}{l}\dot{8} \\
\text { 票 }\end{array}$ & 总 & 景 \\
\hline$\stackrel{\circ}{\stackrel{亠}{O}}$ & 号 & 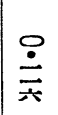 & $\begin{array}{l}\text { 吾 } \\
\text { 簡 }\end{array}$ & & & & $\begin{array}{l}\text { 年 } \\
\text { 温 } \\
\text { 時 }\end{array}$ & $\begin{array}{l}\text { 第 } \\
\text { 吾 } \\
\text { 號 }\end{array}$ & 咅 & 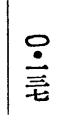 & 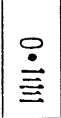 & 兰 & $\stackrel{\stackrel{\varrho}{\Xi}}{\equiv}$ & 兰 & 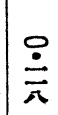 \\
\hline
\end{tabular}




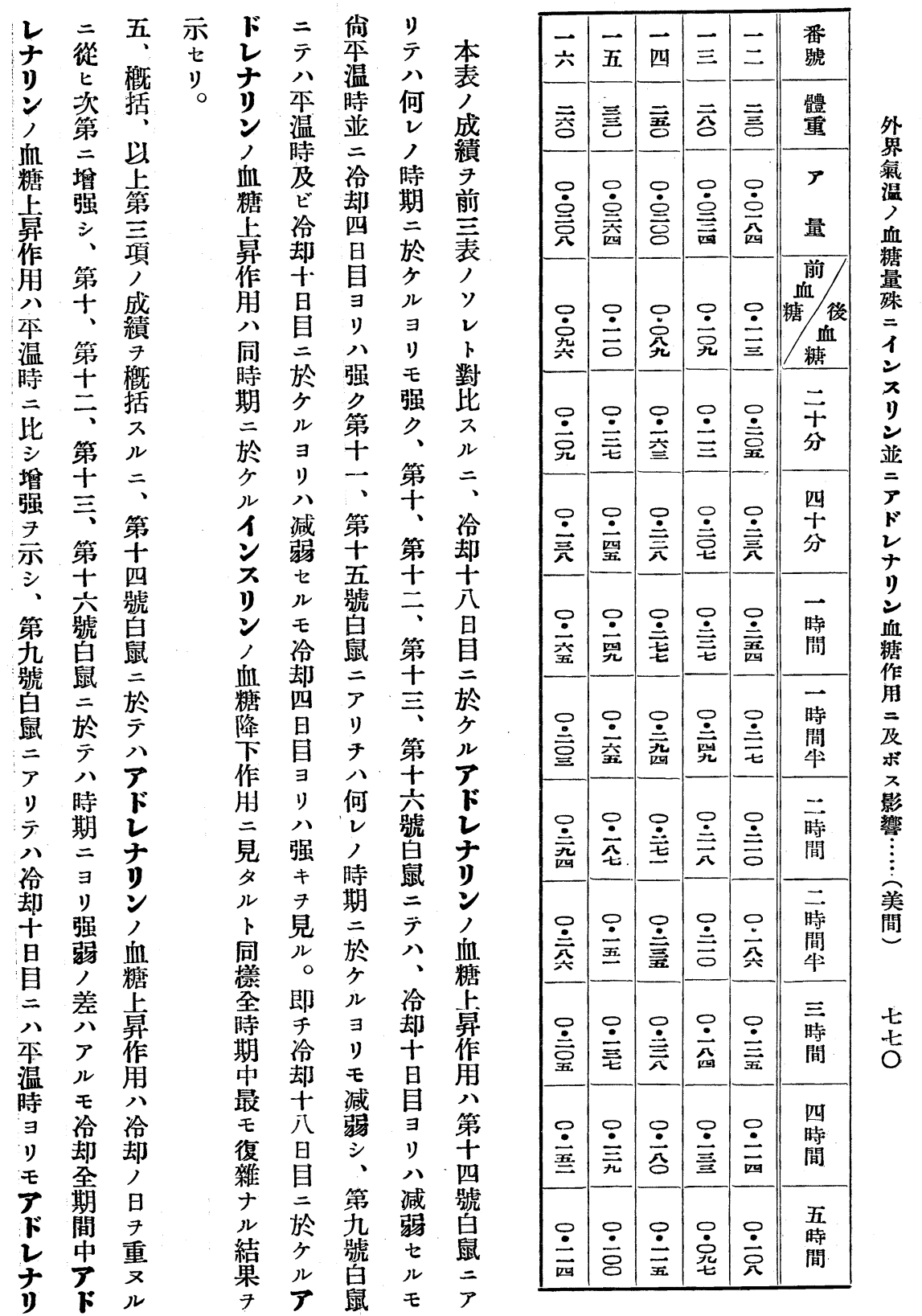



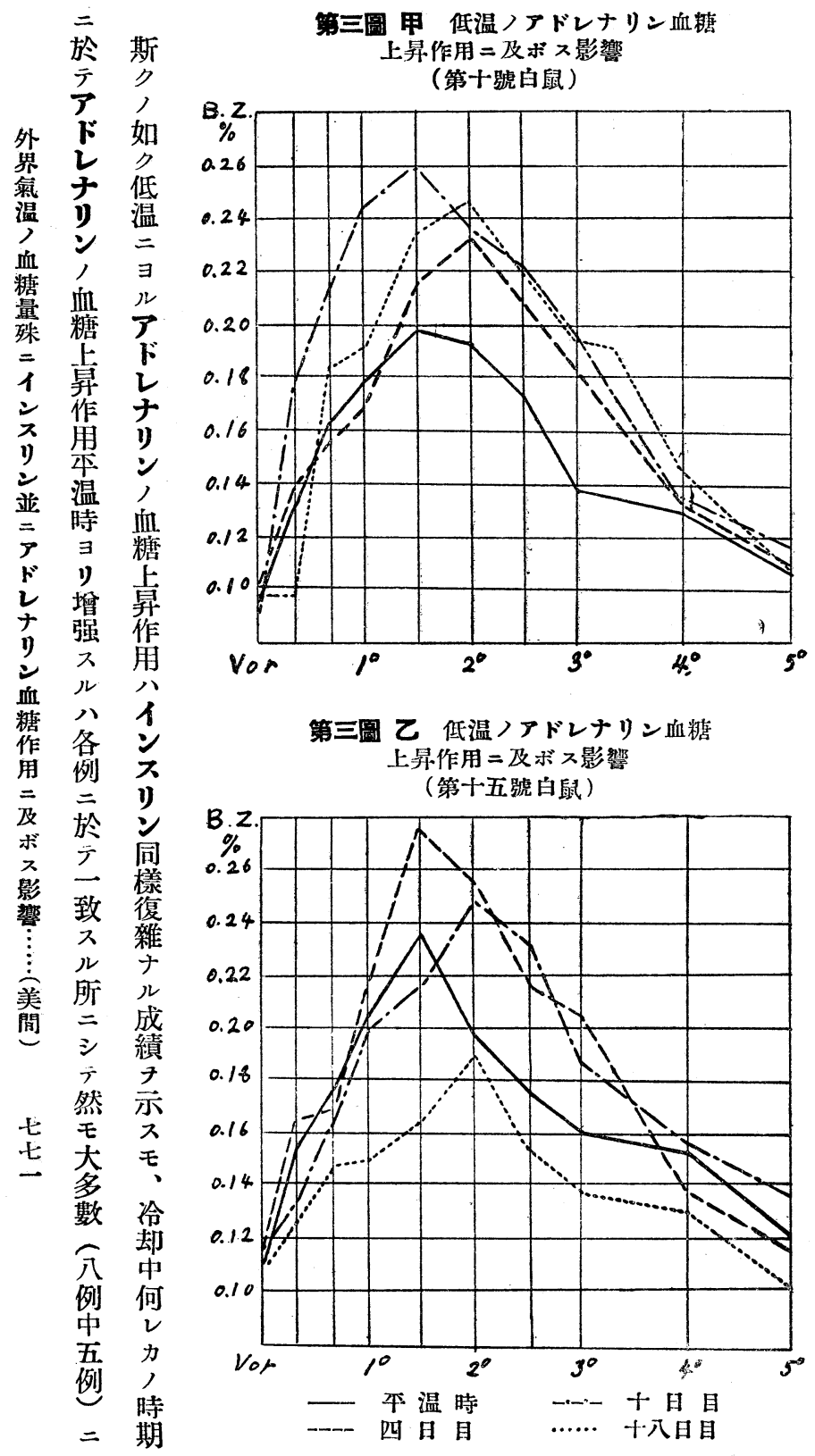

照

照 作

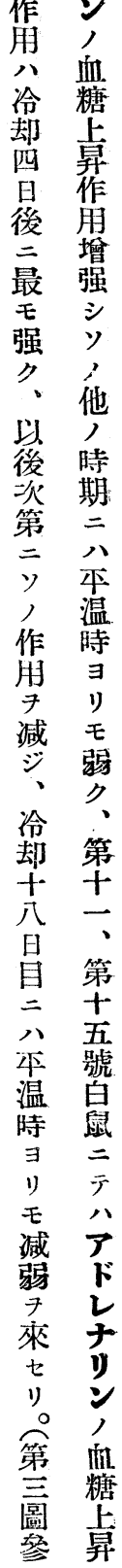




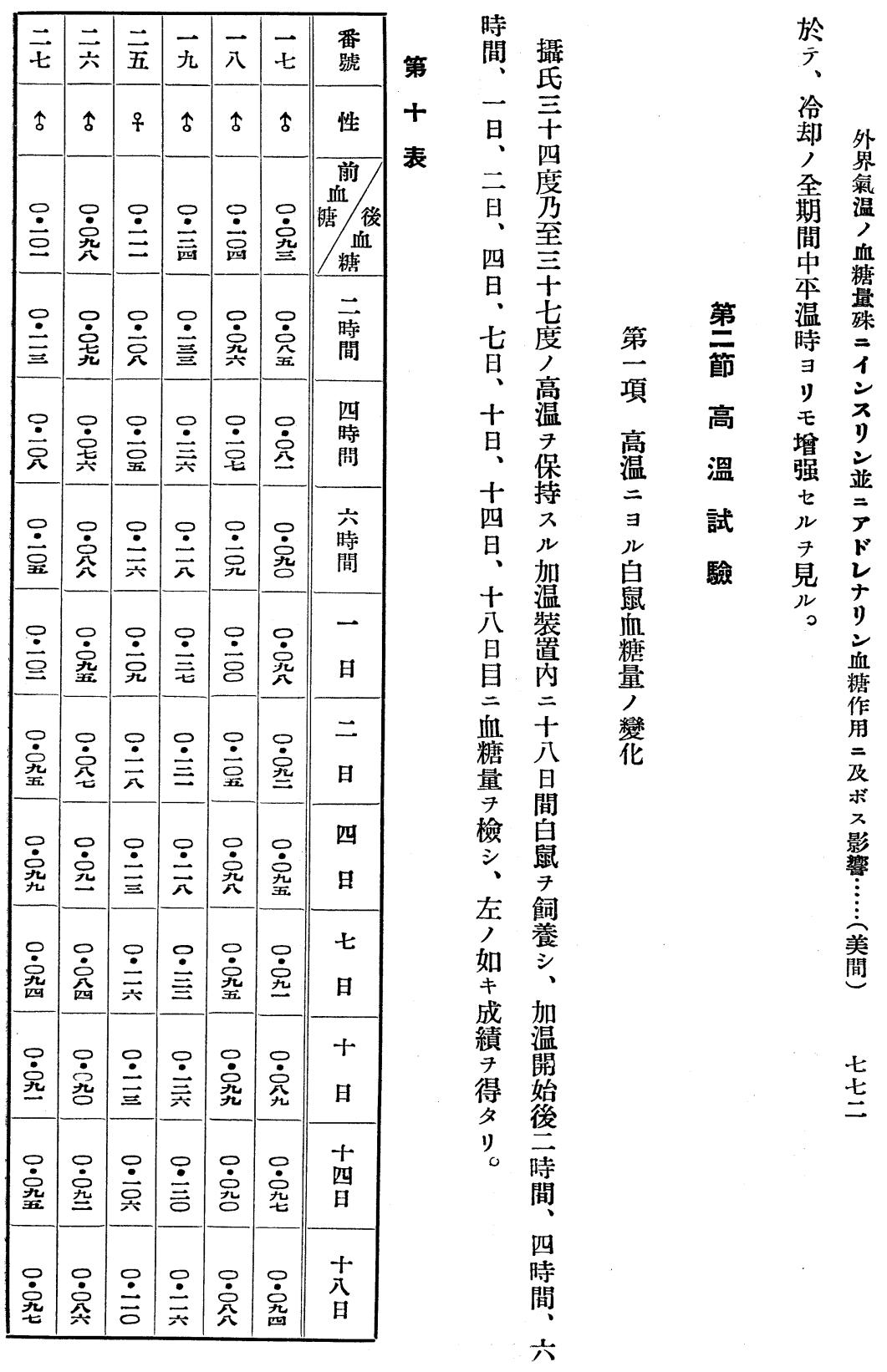


第四圖 甲 第十表, 第十七號白鼠/血糖曲腺

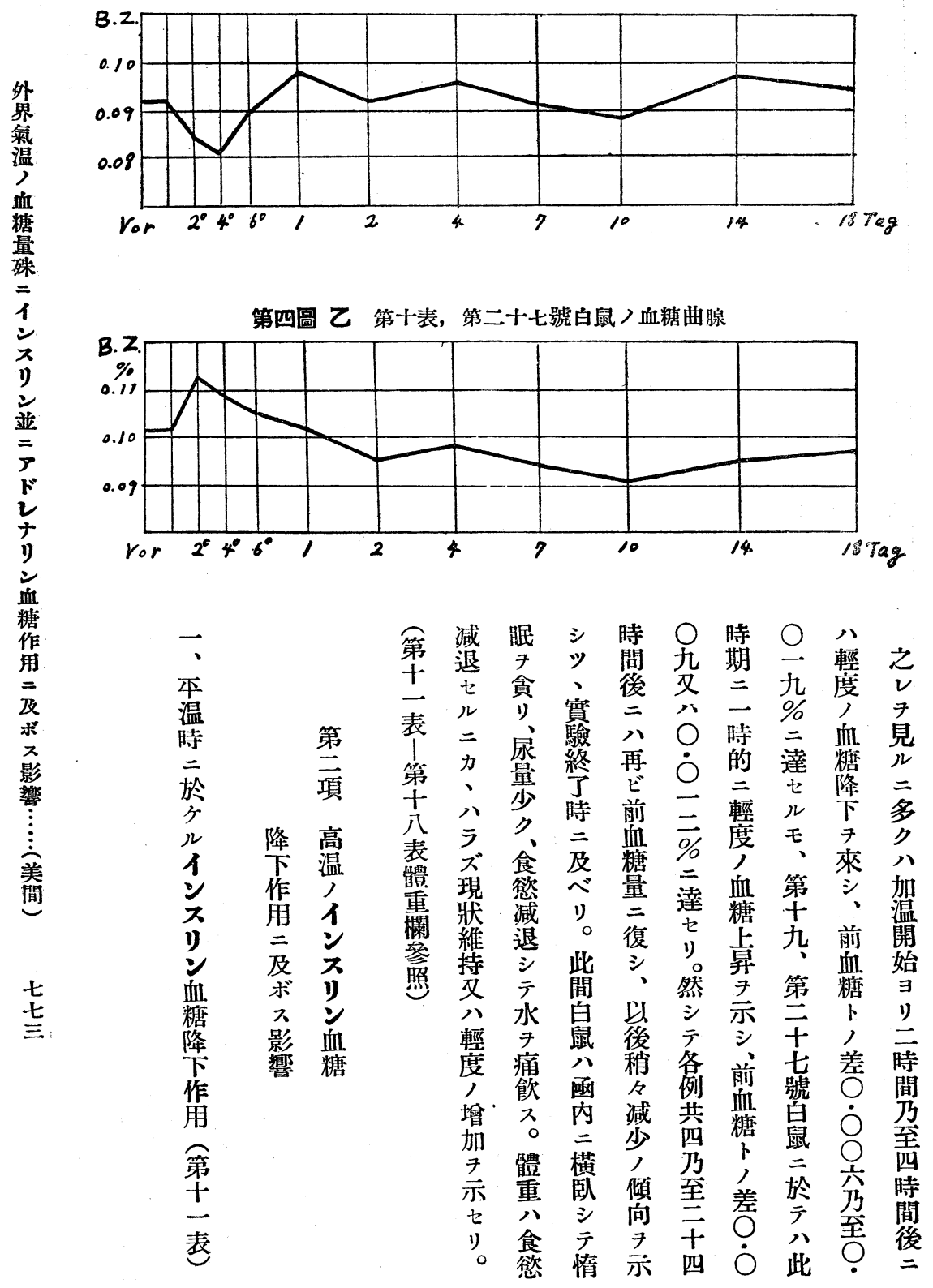




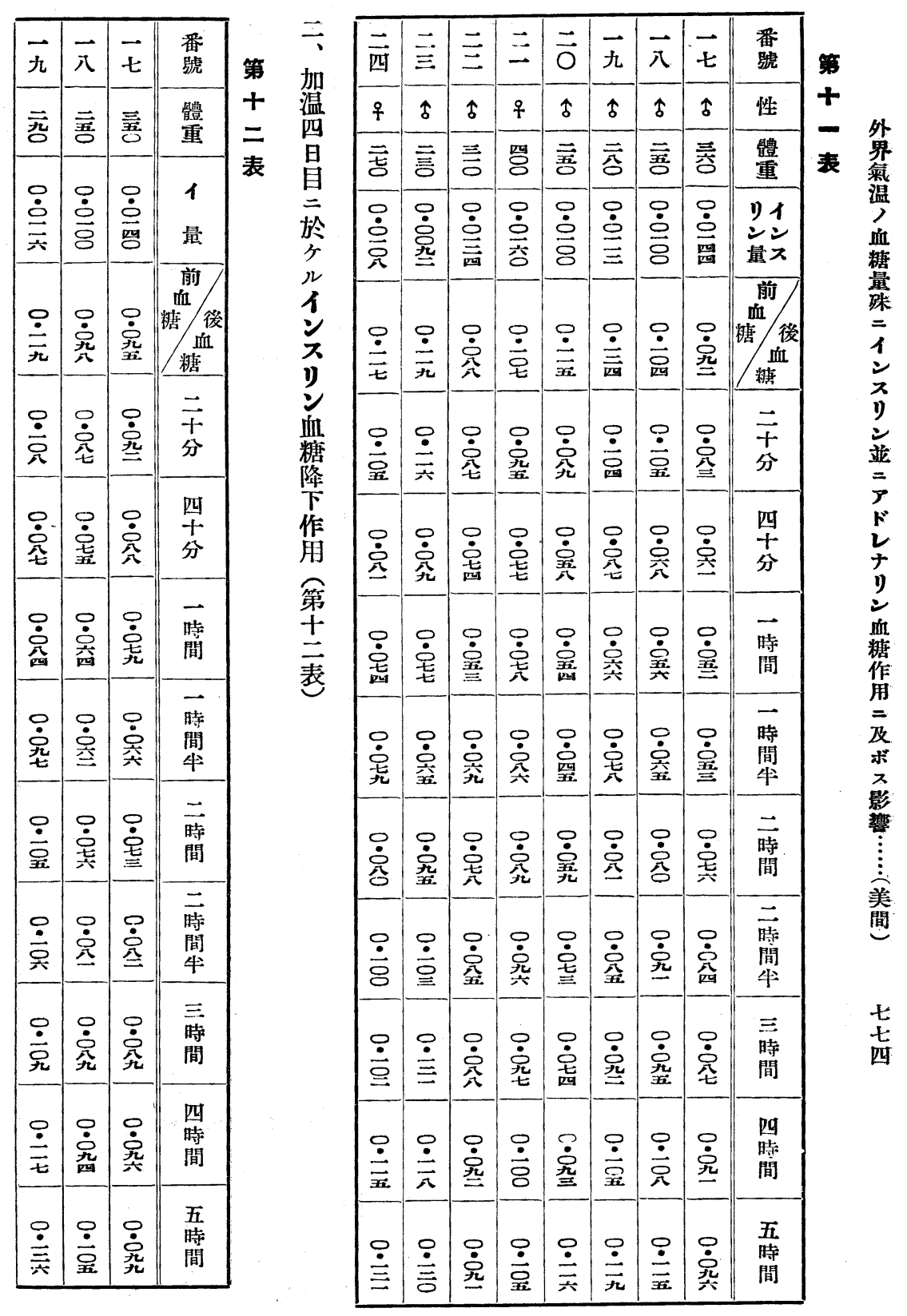




\begin{tabular}{|c|c|c|c|c|c|c|c|c|c|c|c|c|c|c|c|}
\hline$\vec{\nabla}$ & 三 & 三 & $\Xi$ & $\overrightarrow{\overrightarrow{0}}$ & 旮 & $\vec{a}$ & $\vec{t}$ & $\begin{array}{l}\text { 番 } \\
\text { 號 }\end{array}$ & 三 & 右 & $\overrightarrow{\text { 西 }}$ & 主 & 三 & $\equiv$ & $\overrightarrow{\overrightarrow{0}}$ \\
\hline $\bar{\pi}$ & 吾 & 言 & 王 & 言 & 䲶 & 言 & 丞 & $\begin{array}{l}\text { 體 } \\
\text { 重 }\end{array}$ & $\begin{array}{l} \pm \\
\text { 三 }\end{array}$ & 通 & 言 & 言 & 言 & 坖 & 言 \\
\hline $\begin{array}{l}\stackrel{P}{0} \\
\Xi\end{array}$ & $\begin{array}{l}\circ \\
\dot{0} \\
\end{array}$ & $\begin{array}{l}\stackrel{0}{0} \\
\dot{\equiv}\end{array}$ & $\begin{array}{l}0 \\
\dot{0} \\
\text { 全 }\end{array}$ & $\begin{array}{l}0 \\
\dot{0} \\
\text { 兄 }\end{array}$ & 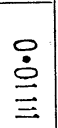 & $\begin{array}{l}0 \\
\dot{0} \\
\text { 兄 }\end{array}$ & \begin{tabular}{l||}
0 \\
$\dot{0}$ \\
至
\end{tabular} & $\begin{array}{l}1 \\
\text { 量 }\end{array}$ & $\begin{array}{l}\text { 目 } \\
\text { 方 }\end{array}$ & $\begin{array}{l}\text { 罢 } \\
\text { ル } \\
= \\
\text { 、 }\end{array}$ & $\begin{array}{l}\stackrel{0}{0} \\
\stackrel{0}{O}\end{array}$ & $\begin{array}{l}\stackrel{8}{\dot{0}} \\
\text { 苯 }\end{array}$ & $\begin{array}{l}\stackrel{0}{0} \\
\stackrel{\overline{0}}{\mathrm{u}}\end{array}$ & $\mid \begin{array}{l}\stackrel{P}{0} \\
\stackrel{\underline{\underline{m}}}{=}\end{array}$ & 兑 \\
\hline$\stackrel{9}{\doteq}$ & $\stackrel{\stackrel{\rho}{\bar{t}}}{ }$ & 完 & 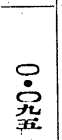 & $\frac{\stackrel{\rho}{\dot{亠}}}{\dot{\pi}}$ & 竎 & $\mid \begin{array}{l}0 \\
\dot{i} \\
\text { 艺 }\end{array}$ & $\begin{array}{l}\dot{\rho} \\
\text { 总 }\end{array}$ & 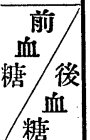 & $\begin{array}{l}u \\
1 \\
y \\
x\end{array}$ & $\begin{array}{l}\text { 各 } \\
\text { 列 } \\
\text { 於 }\end{array}$ & 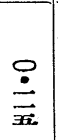 & 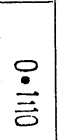 & $\begin{array}{l}0 \\
\dot{0} \\
\text { 全 }\end{array}$ & $\begin{array}{l}\dot{8} \\
\text { 㙂 }\end{array}$ & $\stackrel{\stackrel{\Xi}{\Xi}}{0}$ \\
\hline 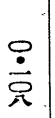 & $\begin{array}{l}\stackrel{9}{\dot{c}} \\
\text { 究 }\end{array}$ & 虽 & $\begin{array}{l}0 \\
\dot{c} \\
\text { 花 }\end{array}$ & $\begin{array}{l}\dot{0} \\
\dot{\alpha} \\
\text { 至 }\end{array}$ & $\begin{array}{l}0 \\
\dot{0} \\
\text { 全 }\end{array}$ & $\mid \begin{array}{l}0 \\
\dot{\dot{c}} \\
\text { 至 }\end{array}$ & 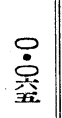 & $\begin{array}{l}\underset{+}{+} \\
\text { 分 }\end{array}$ & $\begin{array}{l}\text { 血 } \\
\text { 糖 }\end{array}$ & $\begin{array}{l}\text { 第 } \\
+ \\
\end{array}$ & 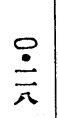 & $\begin{array}{l}\stackrel{\circ}{0} \\
\end{array}$ & $\begin{array}{l}\stackrel{P}{\dot{\alpha}} \\
\text { 完 }\end{array}$ & $\begin{array}{l}\stackrel{0}{0} \\
\text { 是 }\end{array}$ & $\stackrel{O}{\dot{\Xi}}$ \\
\hline 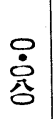 & $\begin{array}{l}0 \\
\dot{0} \\
\stackrel{0}{\equiv}\end{array}$ & 足 & $\begin{array}{l}\stackrel{\circ}{\dot{x}} \\
\text { 突 }\end{array}$ & 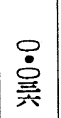 & $\begin{array}{l}0 \\
0 \\
\dot{\underline{t}}\end{array}$ & $\begin{array}{l}0 \\
\dot{0} \\
\text { 空 }\end{array}$ & $\begin{array}{l}\stackrel{0}{\dot{S}} \\
\text { 至 }\end{array}$ & $\begin{array}{l}\text { 四 } \\
\text { 分 }\end{array}$ & 看 & $\begin{array}{l}\text { 莭 } \\
\text { 千 } \\
\text { 年 }\end{array}$ & $\stackrel{\stackrel{\circ}{0}}{\circ}$ & $\begin{array}{l}0 \\
\dot{0} \\
\text { 省 }\end{array}$ & $\begin{array}{l}\stackrel{\rho}{\dot{S}} \\
\text { 突 }\end{array}$ & $\begin{array}{l}\dot{0} \\
\dot{0}\end{array}$ & $\begin{array}{l}0 \\
\dot{0} \\
0\end{array}$ \\
\hline 号 & $\begin{array}{l}0 \\
\dot{c} \\
\text { 塕 }\end{array}$ & $\mid \begin{array}{l}0 \\
\dot{\dot{m}} \\
\text { 突 }\end{array}$ & $\mid \begin{array}{l}0 \\
\dot{c} \\
\text { 究 }\end{array}$ & $\mid \begin{array}{l}0 \\
\dot{0} \\
\text { 芫 }\end{array}$ & $\begin{array}{l}\stackrel{P}{\dot{P}} \\
\text { 올 }\end{array}$ & $\begin{array}{l}\stackrel{0}{0} \\
\dot{5}\end{array}$ & $\mid \begin{array}{c}\stackrel{0}{\dot{\vdots}} \\
\text { 鄫 }\end{array}$ & $\begin{array}{l}\text { 曜 } \\
\text { 間 }\end{array}$ & $\begin{array}{l}\text { 第 } \\
\pm \\
\equiv\end{array}$ & 此 & $\stackrel{\circ}{\grave{O}}$ & $\mid \begin{array}{l}0 \\
\dot{0} \\
\text { 至 }\end{array}$ & $\begin{array}{l}0 \\
\stackrel{0}{0} \\
\text { 空 }\end{array}$ & $\begin{array}{l}\text { 웅 } \\
\text { 突 }\end{array}$ & $\begin{array}{l}\dot{0} \\
\dot{\partial} \\
\text { 亚 }\end{array}$ \\
\hline 号 & $\begin{array}{l}\stackrel{0}{\circ} \\
\text { 尊 } \\
\end{array}$ & $\mid \begin{array}{l}0 \\
\dot{\dot{\theta}} \\
\text { 至 }\end{array}$ & 号 & 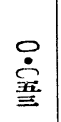 & 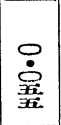 & 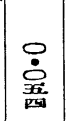 & \begin{tabular}{l||}
$\dot{0}$ \\
$\dot{\dot{g}}$ \\
垔
\end{tabular} & $\begin{array}{l}\text { 晆 } \\
\text { 闈 }\end{array}$ & & $\begin{array}{l}1 \\
y \\
z \\
1\end{array}$ & $\begin{array}{l}\stackrel{0}{\dot{\alpha}} \\
\text { 絰 }\end{array}$ & $\begin{array}{l}0 \\
\dot{c} \\
\text { 突 }\end{array}$ & 㒸 & 号 & 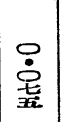 \\
\hline 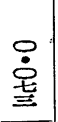 & 总 & $\begin{array}{l}0 \\
\dot{c} \\
\text { 吾 }\end{array}$ & $\begin{array}{l}0 \\
\dot{0} \\
\text { 委 }\end{array}$ & $\begin{array}{l}\dot{P} \\
\dot{P}\end{array}$ & $\begin{array}{l}0 \\
0 \\
\text { 曾 }\end{array}$ & $\mid \begin{array}{l}\dot{0} \\
\dot{\dot{C}} \\
\end{array}$ & \begin{tabular}{l||}
$\dot{0}$ \\
$\dot{0}$ \\
鬲
\end{tabular} & $\begin{array}{l}\overrightarrow{\text { 薪 }} \\
\text { 間 }\end{array}$ & & $\begin{array}{l}2 \\
> \\
\text { 血 }\end{array}$ & 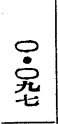 & $\begin{array}{l}\stackrel{0}{0} \\
\text { 究 }\end{array}$ & 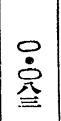 & 号 & $\begin{array}{l}0 \\
\dot{0} \\
\text { 点 }\end{array}$ \\
\hline 号 & 号 & $\begin{array}{l}0 \\
\dot{0} \\
\end{array}$ & 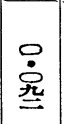 & $\begin{array}{l}8 \\
\text { 宽 }\end{array}$ & 号 & $\begin{array}{l}0 \\
\dot{\dot{c}} \\
\text { 至 }\end{array}$ & 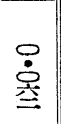 & $\begin{array}{l}\text { 曈 } \\
\text { 閵 } \\
\text { 特 }\end{array}$ & & $\begin{array}{l}\stackrel{\text { 降 }}{F} \\
\text { 作 } \\
\text { 盟 }\end{array}$ & $\begin{array}{l}0 \\
\dot{0} \\
\text { 旮 }\end{array}$ & $\stackrel{\circ}{\dot{\partial}}$ & $\begin{array}{l}0 \\
0 \\
\text { 完 }\end{array}$ & $\begin{array}{l}0 \\
\dot{\dot{c}} \\
\text { 茾 }\end{array}$ & $\begin{array}{l}0 \\
\dot{\alpha} \\
\underline{2}\end{array}$ \\
\hline$\stackrel{\circ}{\stackrel{0}{+}}$ & $\stackrel{\stackrel{\circ}{0}}{0}$ & $\begin{array}{l}\stackrel{0}{\dot{\rho}} \\
\text { 全 }\end{array}$ & $\mid \begin{array}{l}0 \\
\dot{\dot{c}} \\
\text { 茜 }\end{array}$ & $\begin{array}{l}0 \\
\dot{0} \\
\underline{\alpha}\end{array}$ & 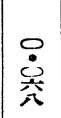 & $\begin{array}{l}0 \\
\text { 案 }\end{array}$ & $\begin{array}{l}0 \\
\dot{0} \\
\text { 至 }\end{array}$ & $\begin{array}{l}\text { 晆 } \\
\text { 間 }\end{array}$ & & $\begin{array}{l}\text { 减 } \\
\text { 弱 } \\
\text { 七 } \\
\text { り }\end{array}$ & 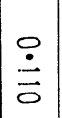 & $\stackrel{8}{\dot{\Xi}}$ & 号 & $\mid \begin{array}{l}0 \\
\dot{\dot{c}} \\
\text { 艺 }\end{array}$ & 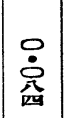 \\
\hline 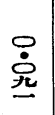 & $\frac{8}{\dot{t}}$ & 号 & 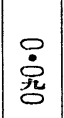 & 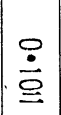 & $\begin{array}{l}0 \\
\text { 军 }\end{array}$ & $\begin{array}{l}\text { 兑 } \\
\text { 突 }\end{array}$ & $\begin{array}{l}0 \\
\dot{i} \\
\text { 总 }\end{array}$ & $\begin{array}{l}\text { 四 } \\
\text { 旺 } \\
\text { 間 }\end{array}$ & & & $\frac{0}{\dot{亠}}$ & $\stackrel{9}{\dot{亠}}$ & $\mid \begin{array}{l}0 \\
\text { 毫 }\end{array}$ & 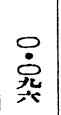 & $\mid \begin{array}{l}0 \\
\dot{\dot{c}} \\
\text { 第 }\end{array}$ \\
\hline$\stackrel{\stackrel{\circ}{\dot{0}}}{\supseteqq}$ & 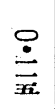 & 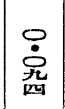 & $\begin{array}{l}\text { 号 } \\
\text { 究 }\end{array}$ & $\stackrel{9}{\dot{\Xi}}$ & $\stackrel{\circ}{\stackrel{\circ}{\circ}}$ & 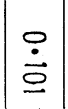 & 兑 & $\begin{array}{l}\text { 吾 } \\
\text { 時 } \\
\text { 間 }\end{array}$ & & & 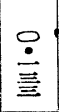 & $\frac{9}{\dot{\bar{x}}}$ & $\begin{array}{l}0 \\
\dot{j} \\
\end{array}$ & $\mid \begin{array}{l}\dot{\dot{P}} \\
\text { 究 }\end{array}$ & 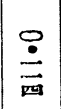 \\
\hline
\end{tabular}




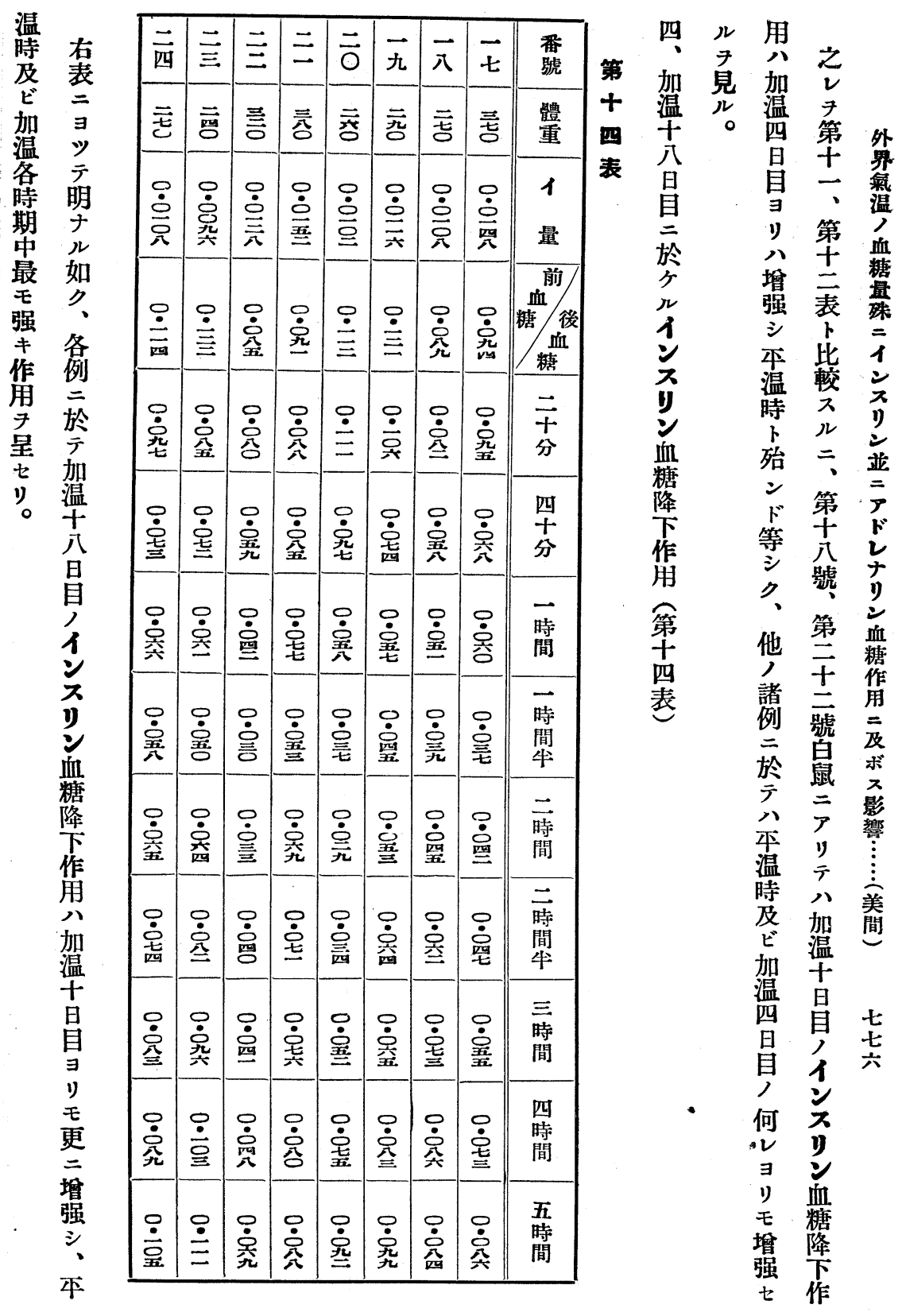




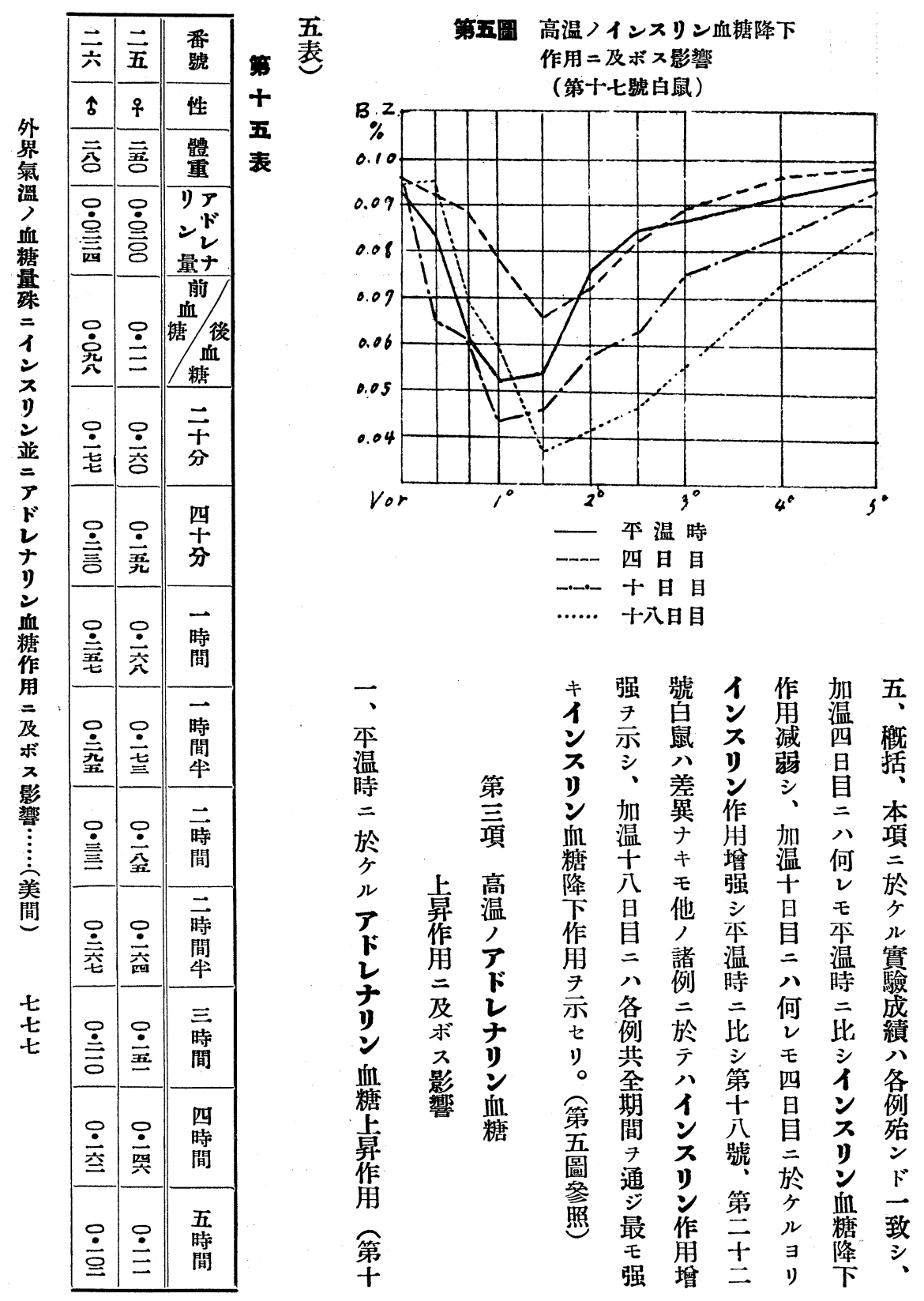




\begin{tabular}{|c|c|c|c|c|c|c|c|c|c|c|c|c|c|c|}
\hline$\equiv$ & $\underset{\vec{\imath}}{\overrightarrow{\mathrm{t}}}$ & $\overrightarrow{\vec{\lambda}}$ & $\vec{t}$ & 亲 & 吾 & $\begin{array}{l}\text { 番 } \\
\text { 䖓 }\end{array}$ & Т & $\equiv$ & $\equiv$ & $\equiv$ & 兊 & 齐 & $\overrightarrow{\mathrm{t}}$ & $\begin{array}{l}\text { 番 } \\
\text { 號 }\end{array}$ \\
\hline 言 & 豆 & 吾 & $\overrightarrow{\overline{\bar{z}}}$ & $\overrightarrow{\bar{\pi}}$ & 吾 & 體 & & $\hat{8}$ & $\hat{\boldsymbol{\delta}}$ & + & 占 & $\hat{\delta}$ & $\hat{\boldsymbol{\delta}}$ & 性 \\
\hline & & & & & & & 表 目 & 家 & 三 & 흥 & 흥 & 言 & 言 & 體 \\
\hline 总 & 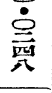 & 总 & $\begin{array}{l}\dot{0} \\
\underline{⿱ 亠 䒑} \\
\end{array}$ & 总 & 㝘 & 量 & 方 & $\begin{array}{l} \\
\dot{0} \\
\text { 劣 }\end{array}$ & 웅 & $\begin{array}{l}\stackrel{0}{0} \\
\text { 亚 }\end{array}$ & $\begin{array}{l} \\
\stackrel{\circ}{\circ} \\
\text { 圈 }\end{array}$ & 号 & 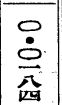 & 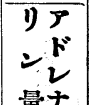 \\
\hline$\frac{8}{8}$ & 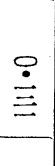 & $\begin{array}{l}\stackrel{0}{0} \\
\text { 䂞 }\end{array}$ & $\begin{array}{l}0 \\
\dot{c} \\
\text { 杂 }\end{array}$ & 完 & 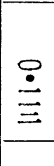 & $\begin{array}{c}\text { 前 } \\
\text { 糖 } \\
\text { 後 } \\
\text { 糖 } \\
\end{array}$ & $\underset{⿱ 乛}{\stackrel{R}{Z}}$ & 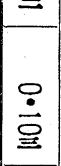 & 完 & $\begin{array}{l}\dot{0} \\
\dot{0} \\
\end{array}$ & $\stackrel{\stackrel{\rho}{\Xi}}{\pi}$ & 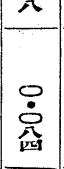 & $\stackrel{\dot{\dot{O}}}{0}$ & 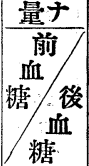 \\
\hline 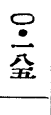 & $\stackrel{\circ}{\stackrel{\circ}{\dot{0}}}$ & $\stackrel{\circ}{\dot{ }}$ & 号 & $\frac{\stackrel{9}{\dot{\theta}}}{\text { 吾 }}$ & 兰 & 召 & 血 & 号 & 兰 & 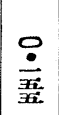 & 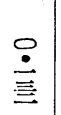 & $\mid \begin{array}{l}0 \\
\dot{\dot{c}} \\
\text { 足 }\end{array}$ & $\left|\begin{array}{l}0 \\
\dot{\dot{t}} \\
\text { 苪 }\end{array}\right|$ & $\begin{array}{l}\overrightarrow{+} \\
\underset{7}{\text { 分 }}\end{array}$ \\
\hline$\stackrel{\circ}{\stackrel{\circ}{\text { 芦 }}}$ & $\stackrel{\circ}{\stackrel{\circ}{\vec{x}}}$ & 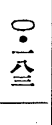 & 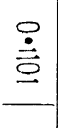 & 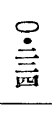 & 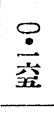 & $\begin{array}{l}\text { 四 } \\
+ \\
\text { 分 }\end{array}$ & $\begin{array}{l}\text { 昇 } \\
\text { 㤰 }\end{array}$ & $\stackrel{\stackrel{\rho}{\dot{\vec{x}}}}{\text { 五 }}$ & 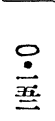 & $\frac{\stackrel{9}{\dot{\vec{x}}}}{\text { 吾 }}$ & 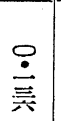 & $\mid \begin{array}{l}0 \\
\dot{\text { 窝 }}\end{array}$ & 兰 & $\begin{array}{l}\text { 四 } \\
+ \\
\text { 分 }\end{array}$ \\
\hline 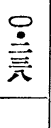 & 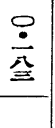 & $\stackrel{\circ}{\grave{\grave{g}}}$ & $\stackrel{\stackrel{\rho}{\overline{\bar{x}}}}{\text { 五 }}$ & 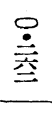 & 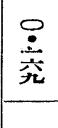 & 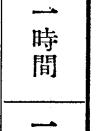 & & 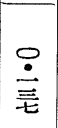 & $\stackrel{\circ}{\dot{\bar{\delta}}}$ & 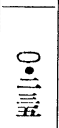 & 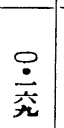 & 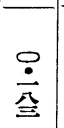 & 咅 & $\begin{array}{l}\overrightarrow{\text { 黙 }} \\
\text { 間 }\end{array}$ \\
\hline 号 & $\stackrel{\circ}{\dot{\grave{\lambda}}}$ & 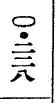 & 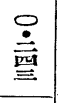 & 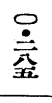 & 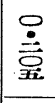 & $\begin{array}{l}\text { 時 } \\
\text { 間 } \\
\text { 米 }\end{array}$ & & $\frac{\stackrel{P}{\dot{\vec{v}}}}{\underline{\underline{\underline{\underline{g}}}}}$ & 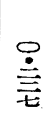 & 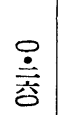 & $\stackrel{\circ}{\dot{\pi}}$ & $\stackrel{0}{\dot{\equiv}}$ & 畜 & $\begin{array}{l}\text { 晆 } \\
\text { 間 } \\
\text { 年 }\end{array}$ \\
\hline$\stackrel{ᄋ}{\dot{\bar{n}}}$ & 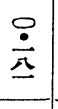 & 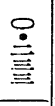 & $\stackrel{\circ}{\dot{\bar{\theta}}}$ & 总 & $\stackrel{8}{\dot{\underline{\beta}}}$ & $\begin{array}{l}\text { 鬲 } \\
\text { 留 }\end{array}$ & & 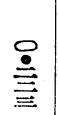 & $\stackrel{\stackrel{\rho}{\Xi}}{ }$ & 咅 & 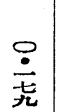 & $\stackrel{\circ}{\stackrel{\Xi}{\Xi}}$ & 兰 & $\begin{array}{l}\text { 雟 } \\
\text { 間 }\end{array}$ \\
\hline 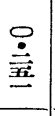 & $\stackrel{\circ}{\dot{\dot{x}}}$ & $\stackrel{\circ}{\dot{\bar{\partial}}}$ & 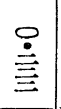 & $\stackrel{\circ}{\stackrel{\circ}{\underline{\underline{z}}}}$ & $\stackrel{\stackrel{\rho}{\dot{\epsilon}}}{\underline{\underline{E}}}$ & 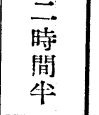 & & $\stackrel{\circ}{\grave{0}}$ & 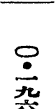 & $\stackrel{\circ}{\dot{\bar{t}}}$ & $\stackrel{\circ}{\dot{0}}$ & $\stackrel{\circ}{\dot{\bar{E}}}$ & $\frac{0}{\dot{\pi}}$ & $\begin{array}{l}\overrightarrow{\text { 時 }} \\
\text { 間 }\end{array}$ \\
\hline 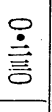 & $\stackrel{\circ}{\dot{\Xi}}$ & $\begin{array}{l}\stackrel{0}{\circ} \\
\dot{\overline{0}}\end{array}$ & 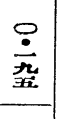 & $\stackrel{\circ}{\grave{\bar{\Xi}}}$ & 竞 & $\begin{array}{l}\text { 軖 } \\
\text { 間 }\end{array}$ & & 足 & 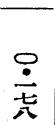 & $\stackrel{\stackrel{9}{\grave{\lambda}}}{\text { 亲 }}$ & 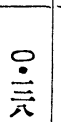 & $\stackrel{\circ}{\stackrel{\circ}{\text { 公 }}}$ & $\stackrel{?}{\stackrel{9}{\dot{\Lambda}}}$ & $\begin{array}{l}\text { 㤩 } \\
\text { 㶕 }\end{array}$ \\
\hline$\stackrel{\text { 号 }}{\text { 吾 }}$ & 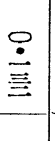 & 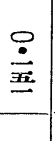 & 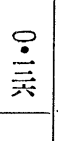 & $\stackrel{\circ}{\stackrel{\Xi}{\text { 元 }}}$ & 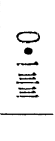 & $\begin{array}{l}\text { 四 } \\
\text { 時 } \\
\text { 間 }\end{array}$ & & 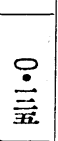 & 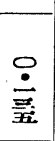 & $\stackrel{\stackrel{\circ}{\dot{\dot{g}}}}{\text { 尊 }}$ & $\stackrel{\circ}{\stackrel{\Xi}{\Xi}}$ & 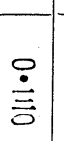 & $\stackrel{\stackrel{\circ}{\Xi}}{\text { 京 }}$ & $\begin{array}{l}\text { 四 } \\
\text { 簡 }\end{array}$ \\
\hline 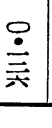 & $\stackrel{P}{\dot{\Xi}}$ & 总 & 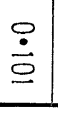 & 完 & 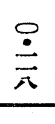 & $\begin{array}{l}\text { 吾 } \\
\text { 晧 }\end{array}$ & & $\stackrel{ }{\dot{\Xi}}$ & $\begin{array}{l}\text { 㝓 } \\
\text { 等 }\end{array}$ & $\stackrel{\stackrel{一}{\Xi}}{\equiv}$ & 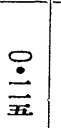 & 兑 & 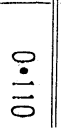 & $\begin{array}{l}\text { 吾 } \\
\text { 時 } \\
\text { 間 }\end{array}$ \\
\hline
\end{tabular}




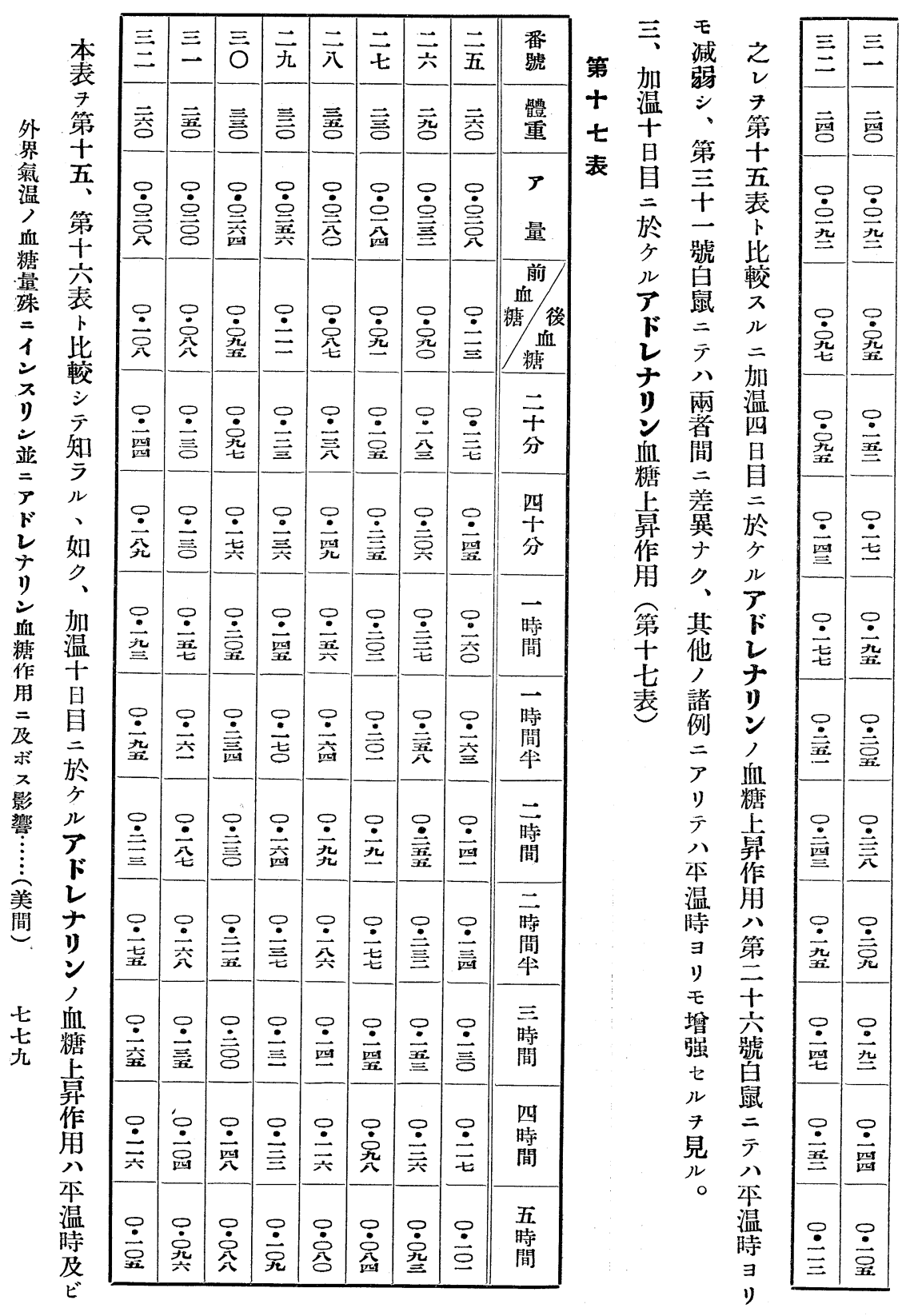




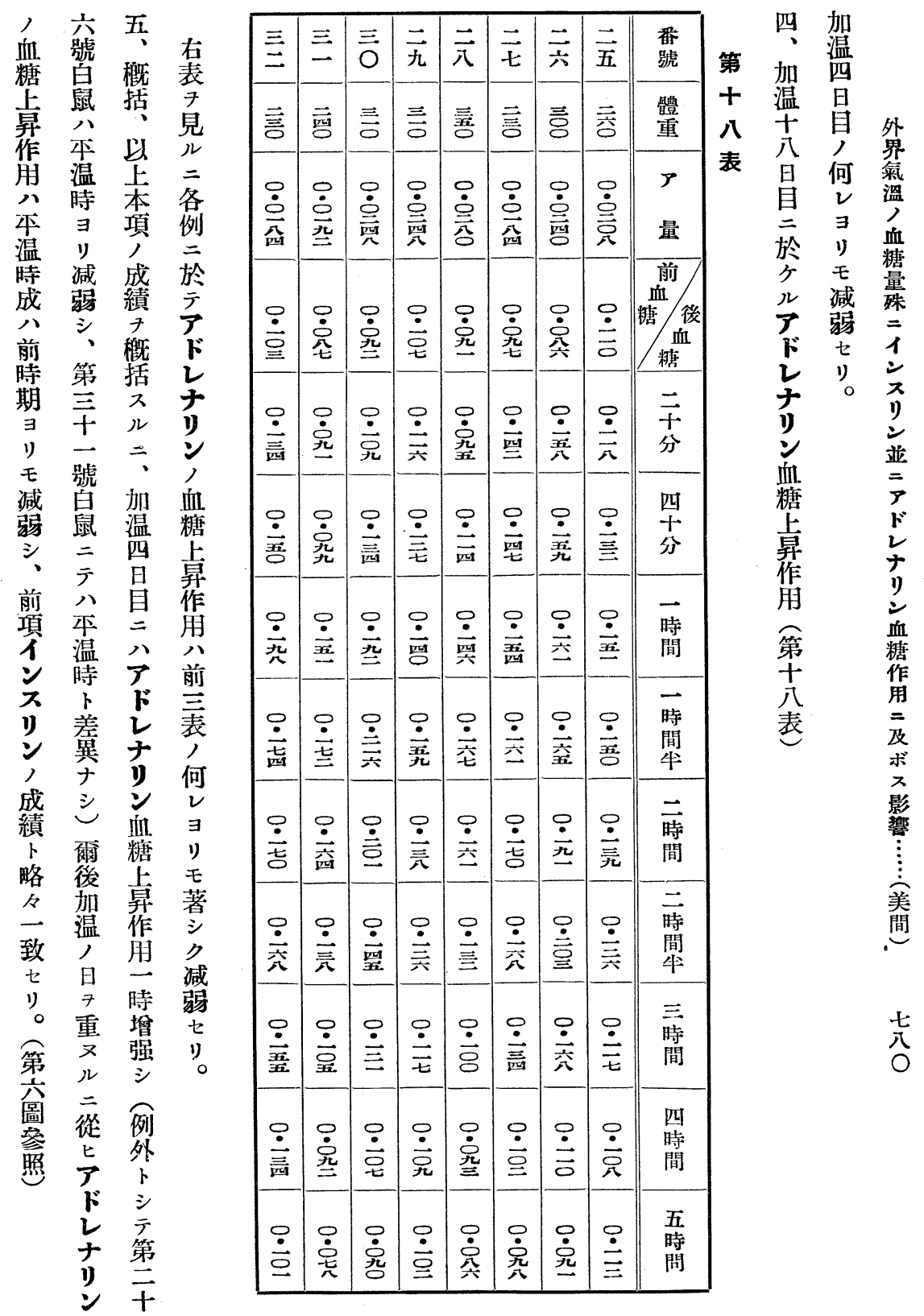




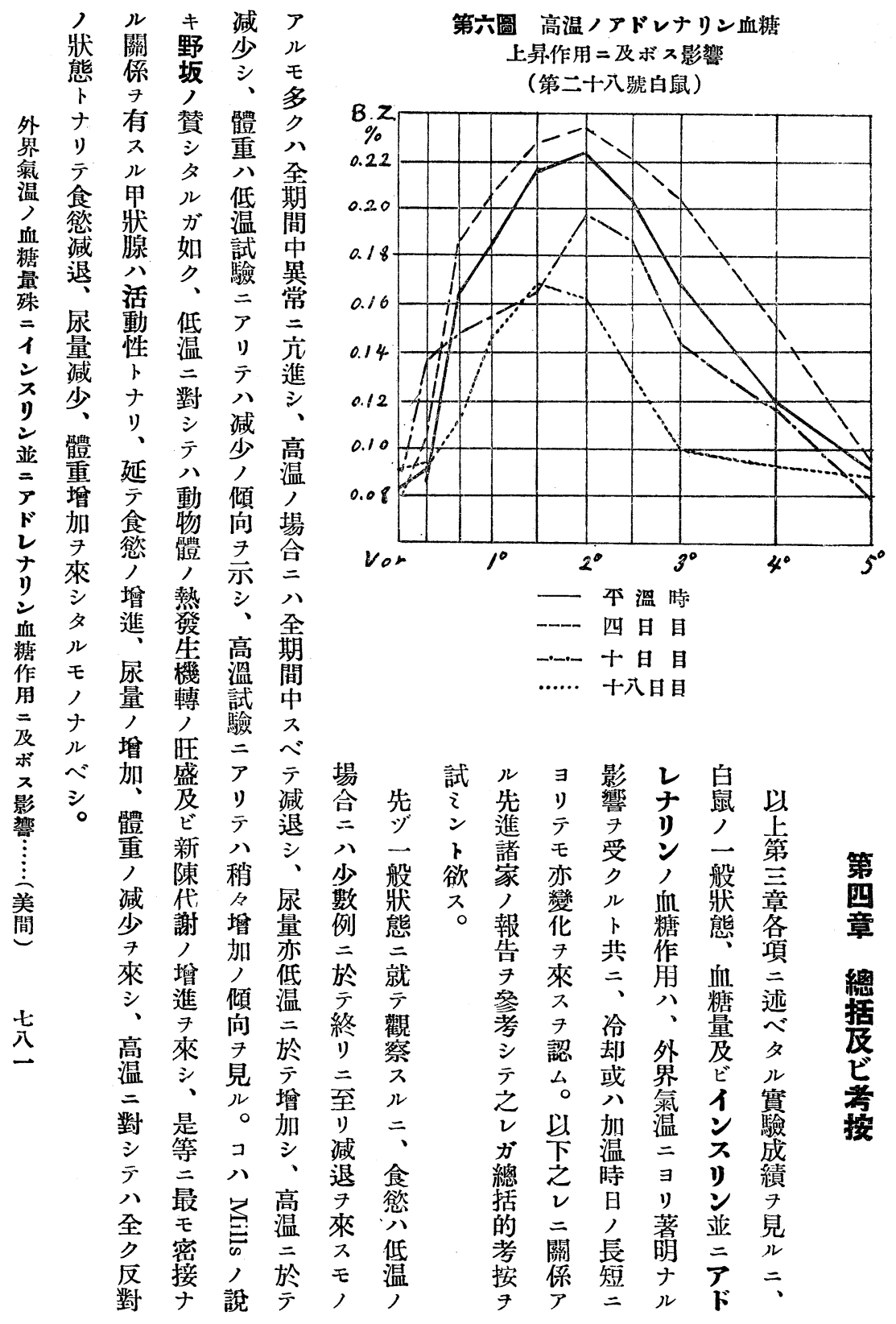




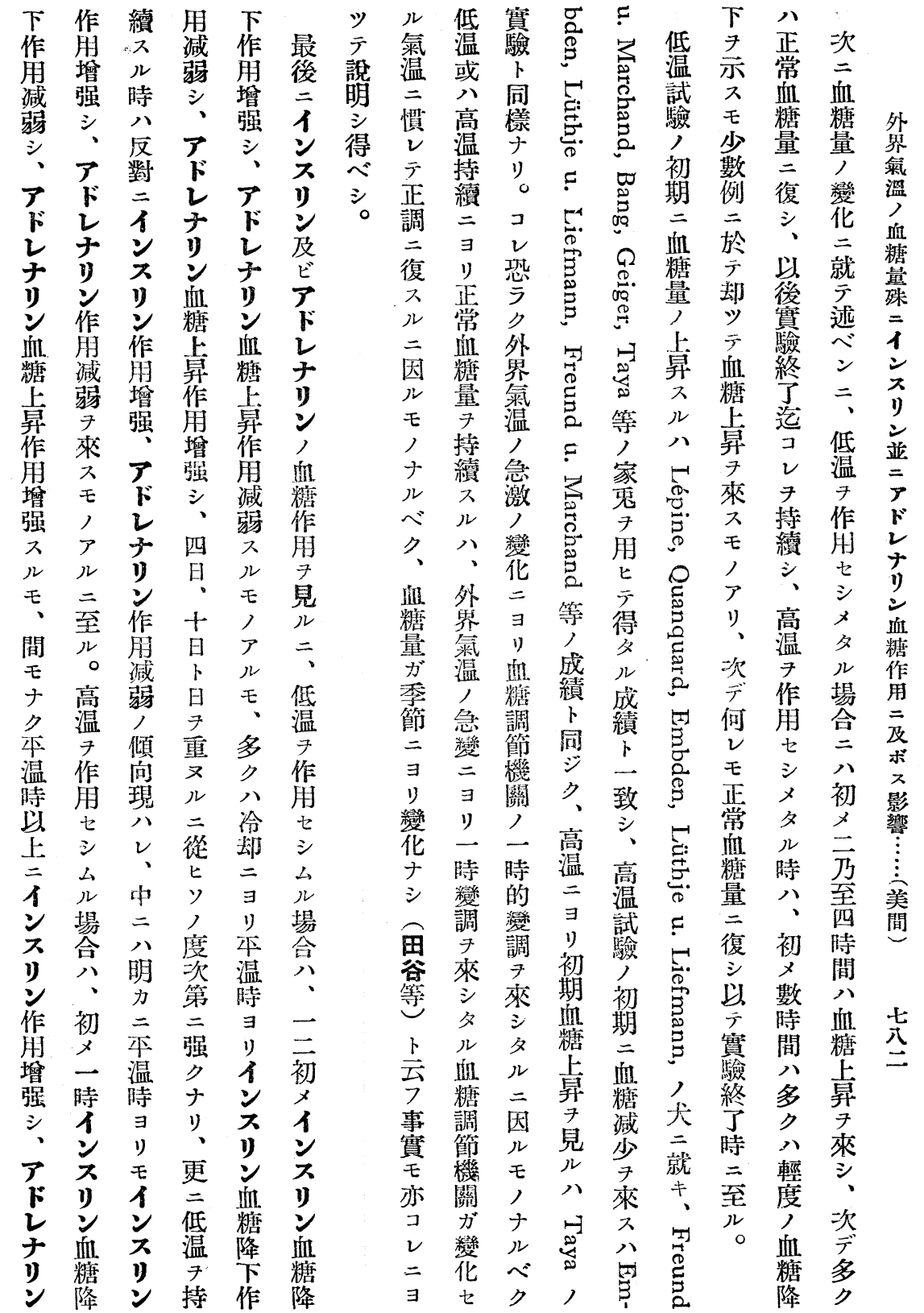




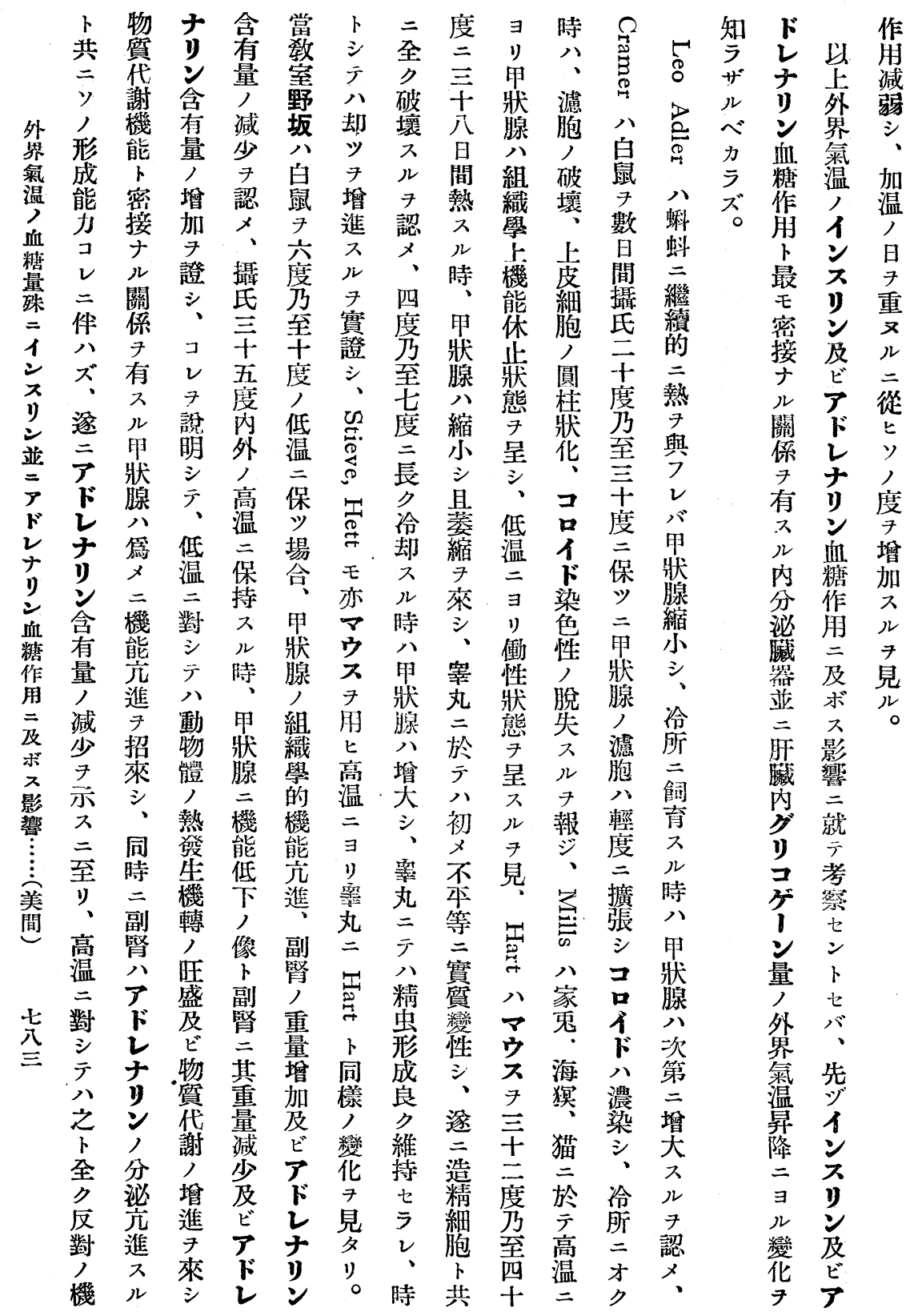




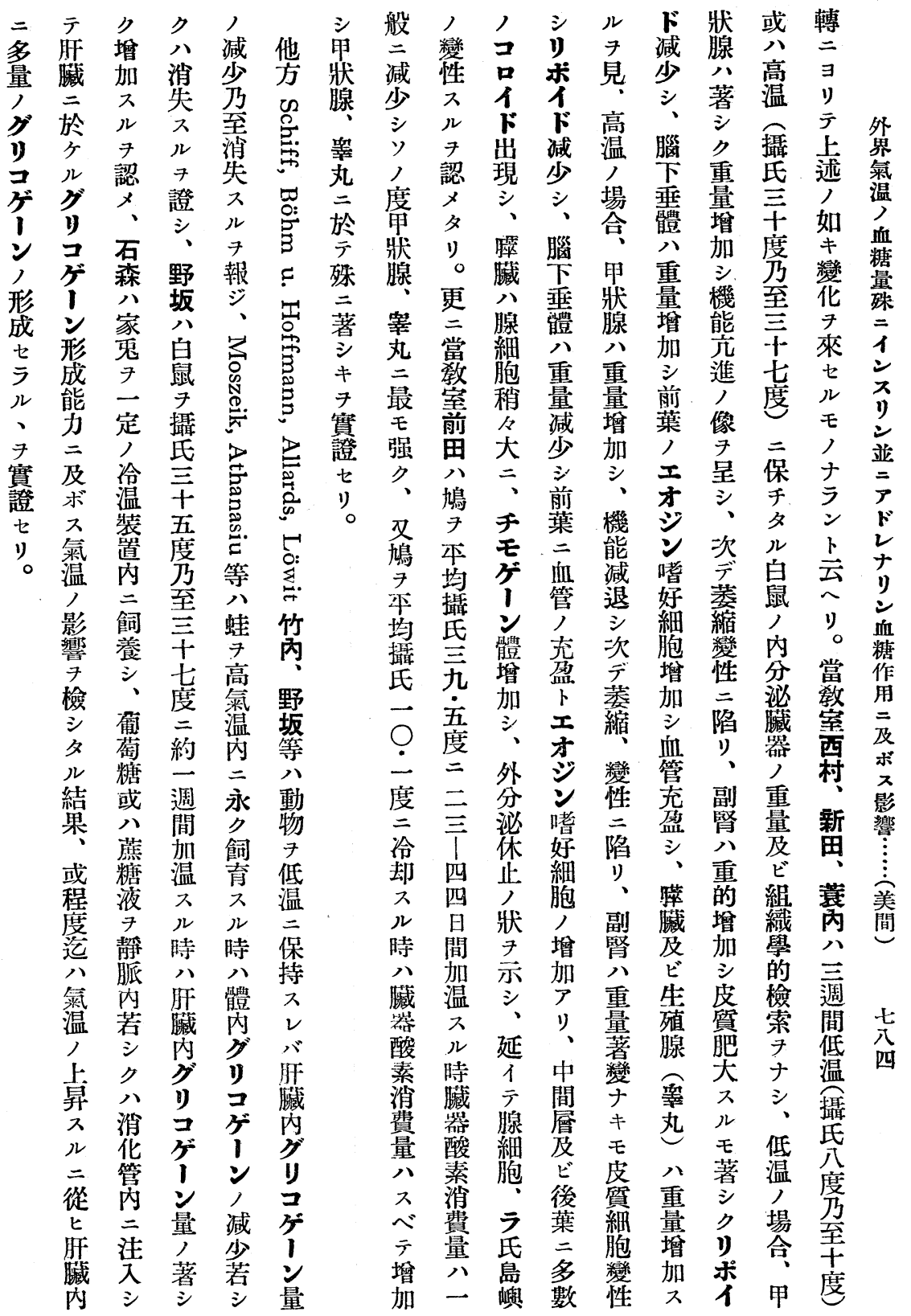




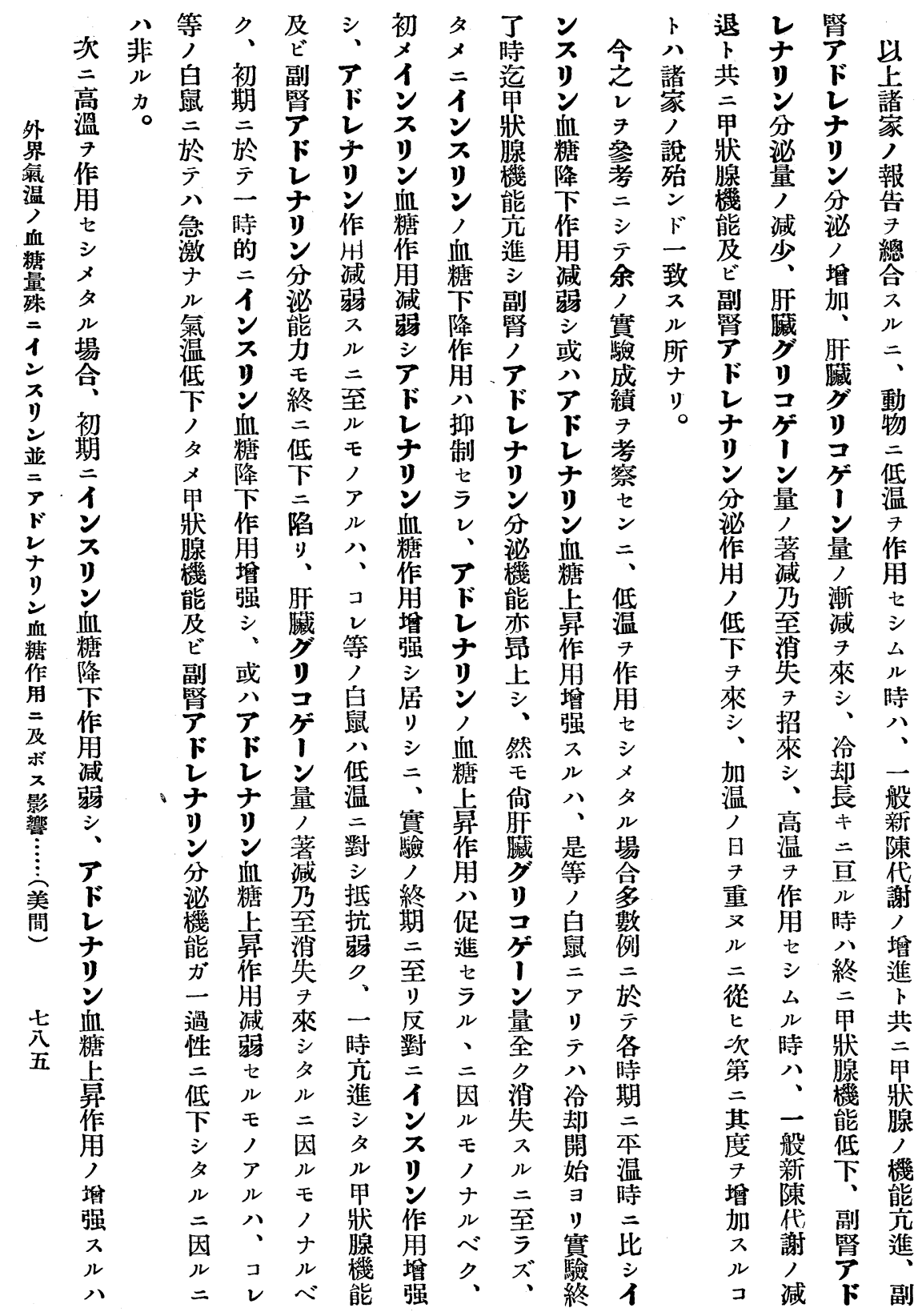




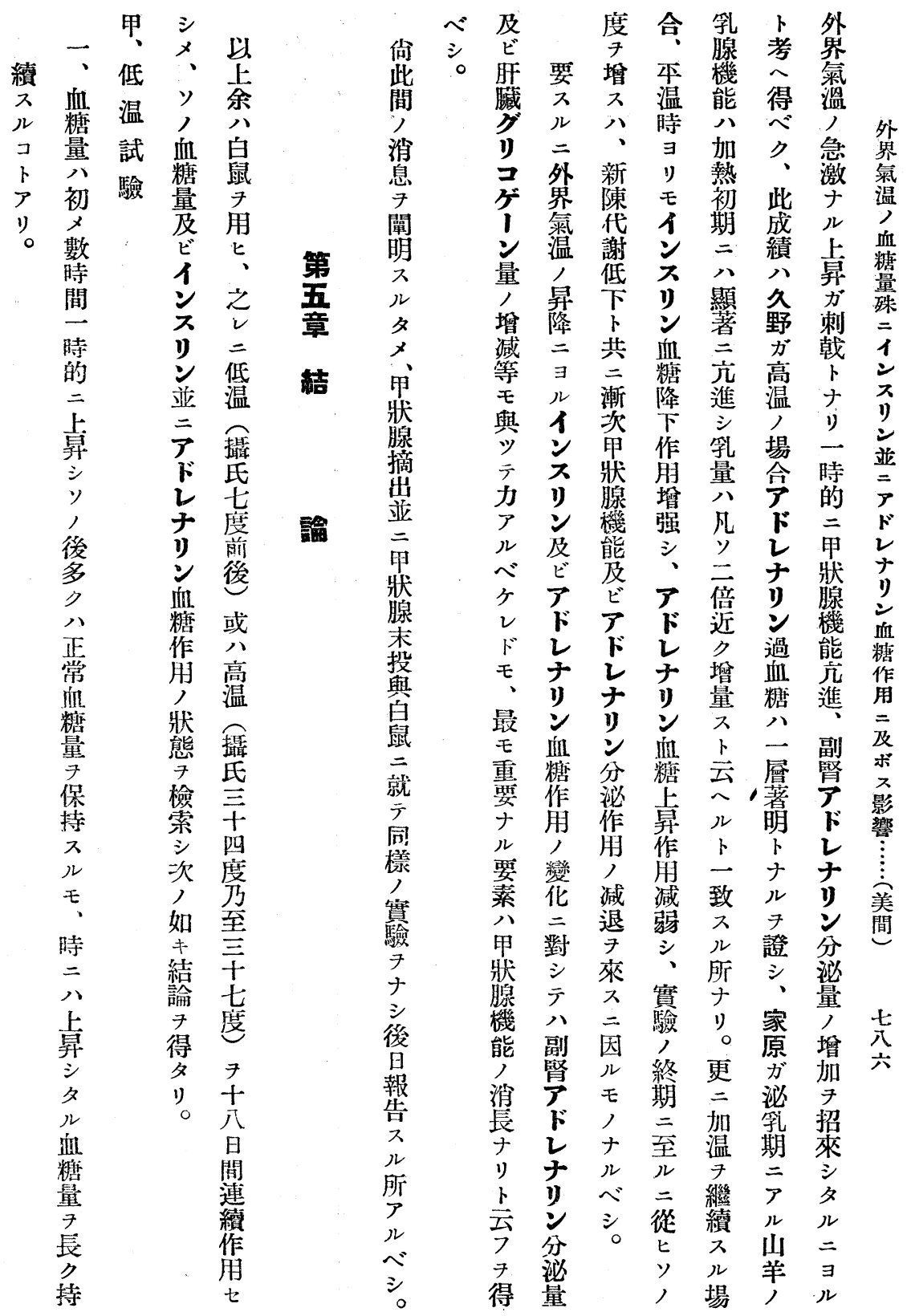




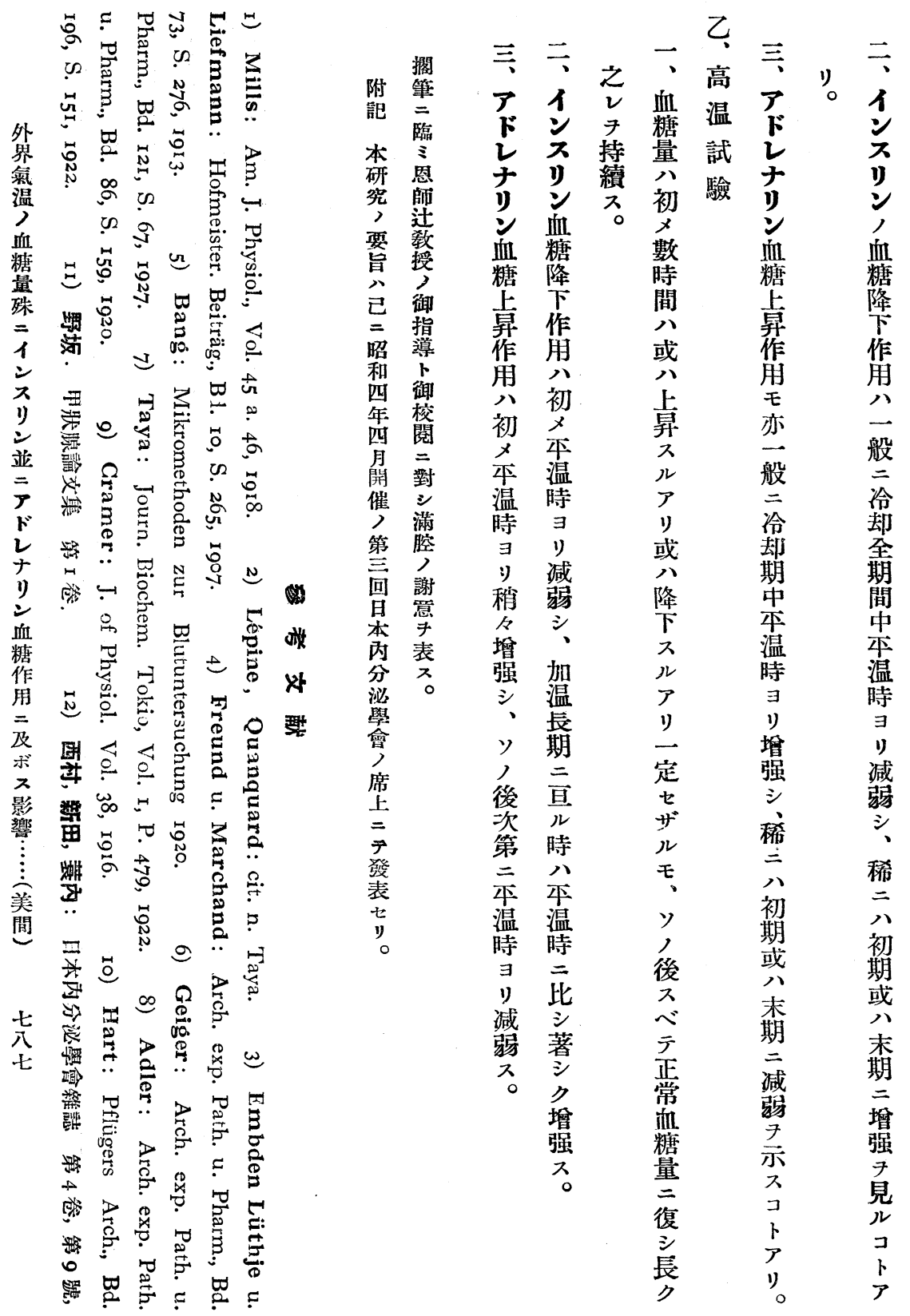




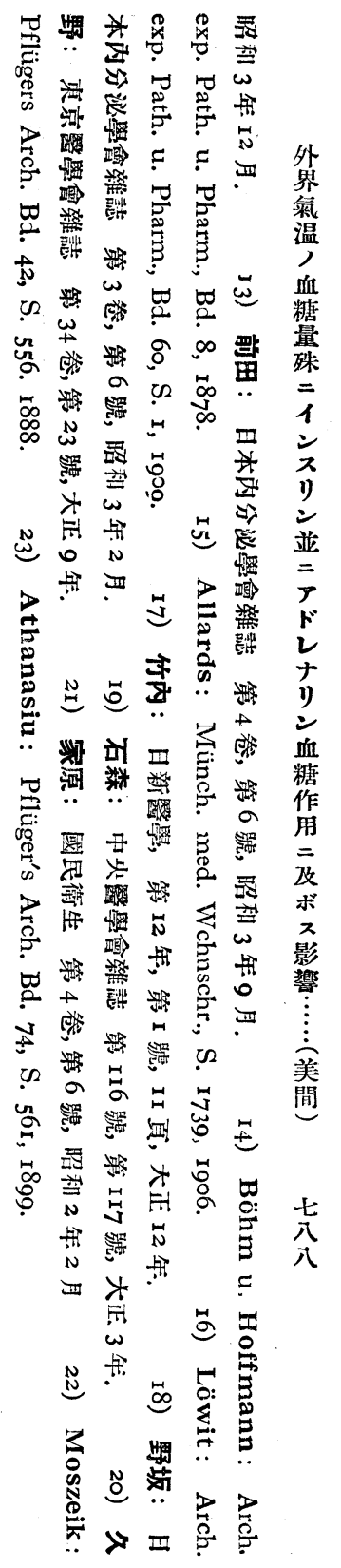


der Thyreoidea durch die direkte Reizwirkung des Teers zustande kommen.

(Autoreferat.)

\section{Ueber den Einfluss der Aussentemperatur auf den Zuckerstoffwechsel bei Ratten. (I. und II. Mitteilung)}

Von

Dr. T. Mima.

(Aus der I. med. Klinik der Kaiserl. Univers. zu Kyoto, Japan. Direktor: Prof. Dr. K. Tsuji.)

Um die Beziehung zwischen der Aussentemperatur und dem Zuckerstoffwechsel kennen zu lernen und weiter um die Rolle der Schilddrüse bei der chemischen Wärmeregulation klar zu legen, beobachtete der Verfasser die Veränderungen des Blutzuckerspiegels und der Insulin- und Adrenalinblutzuckerwirkungen an normalen, schilddrüsenlosen und mit Schilddrüsenpulver gefütterten Ratten, die I8 Tage lang bei erniedrigter (ca. $7^{\circ} \mathrm{C}$.) oder erhöhter (ca. $35^{\circ} \mathrm{C}$.) Aussentemperatur gehalten wurden. Die Resultate sind bei derselben Temperatur qualitativ bei allen Ratten sehr ähnlich, aber quantitativ (im Grad der Veränderungen) ganz verschieden, nämlich bei den schilddrüsenlosen Ratten schwächer und bei mit Schilddrüsenpulver gefütterten stärker als bei normalen.

Die Resultate bei normalen Ratten lassen sich wie folgt zusammenfassen : -

A. Bei erniedrigter Aussentemperatur :

I) Der Blutzucker steigt sofort nach dem Abkühlen an, erreicht nach 2-6 Stunden seinen maximalen Wert und fällt dann bis zum normalen.

2) Mit dem Abkühlen wird die Insulinhypoglykämie immer 
schwächer und die Adrenalinhyperglykämie immer stärker als bei Zimmertemperatur.

B. Bei erhöhter Aussentemperatur :

I) Der Blutzucker steigt bei einigen Fällen an und fällt bei anderen Fällen sofort nach dem Warmwerden. Doch erreichen alle Fälle nach $2-6$ Stunden den maximalen Wert und später den normalen.

2) Im Frühstadium wird die Insulinhypoglykämie schwächer und die Adrenalinhyperglykämie stärker als bei Zimmertemperatur, aber im Mittel- und Spätstadium ist es gerade umgekehrt.

(Autoreferat)

\title{
Ueber den Einfluss des Hodens auf die Organ- milchsäure und das Lactacidogen des Muskels und der Leber.
}

\author{
Von
}

Dr. K. Tanaka

(Aus der I. med. Klinik der Kaiserlichen Universität zu Kyoto, Japan. Direktor: Prof. Dr. K. Tsuji.)

Um den Einfluss der verschiedenen innersekretorischen Organe auf den Milschsäure- und Lactacidogenstoffwechsel festzustellen, hat der Verfasser Versuche an Kaninchen angestellt.

Die Milchsäurebestimmung wurde nach der Embden-HirschKaufmannschen Methode und die Lactacidogenbestimmung nach der Embden-Teradaschen Methode ausgeführt.

Die Resultate in bezug auf den Hoden sind die folgenden:

I) Bei der Darreichung von Hodenpulver neigt die Milchsaüre im Ohrvenen- und Karotisblute zur Vermehrung.

2) Bei der Hodenexstirpation zeigt die Milchsäure im Ohrvenen- und Karotisblute Verminderung.

3) Bei den mit Hodenpulver gefütterten Kaninchen tritt die 